\title{
Treatment of cognitive impairment in schizophrenia: potential value of phosphodiesterase inhibitors in prefrontal dysfunction
}

Citation for published version (APA):

van Duinen, M., Reneerkens, O. A. H., Lambrecht, L., Sambeth, A., Rutten, B. P. F., van Os, J., Blokland, A., \& Prickaerts, J. (2015). Treatment of cognitive impairment in schizophrenia: potential value of phosphodiesterase inhibitors in prefrontal dysfunction. Current Pharmaceutical Design, 21(26), 38133828. https://doi.org/10.2174/1381612821666150605110941

Document status and date:

Published: 01/01/2015

DOI:

10.2174/1381612821666150605110941

Document Version:

Publisher's PDF, also known as Version of record

Document license:

Taverne

Please check the document version of this publication:

- A submitted manuscript is the version of the article upon submission and before peer-review. There can be important differences between the submitted version and the official published version of record.

People interested in the research are advised to contact the author for the final version of the publication, or visit the DOI to the publisher's website.

- The final author version and the galley proof are versions of the publication after peer review.

- The final published version features the final layout of the paper including the volume, issue and page numbers.

Link to publication

\footnotetext{
General rights rights.

- You may freely distribute the URL identifying the publication in the public portal. please follow below link for the End User Agreement:

www.umlib.nl/taverne-license

Take down policy

If you believe that this document breaches copyright please contact us at:

repository@maastrichtuniversity.nl

providing details and we will investigate your claim.
}

Copyright and moral rights for the publications made accessible in the public portal are retained by the authors and/or other copyright owners and it is a condition of accessing publications that users recognise and abide by the legal requirements associated with these

- Users may download and print one copy of any publication from the public portal for the purpose of private study or research.

- You may not further distribute the material or use it for any profit-making activity or commercial gain

If the publication is distributed under the terms of Article 25fa of the Dutch Copyright Act, indicated by the "Taverne" license above, 


\title{
Treatment of Cognitive Impairment in Schizophrenia: Potential Value of Phosphodi- esterase Inhibitors in Prefrontal Dysfunction
}

\author{
M.A. Van Duinen ${ }^{1}$, O.A.H. Reneerkens ${ }^{2}$, L. Lambrecht ${ }^{3}$, A. Sambeth ${ }^{4}$, B.P.F. Rutten ${ }^{1}$, J. Van Os ${ }^{1}$, A. \\ Blokland ${ }^{4}$ and J. Prickaerts ${ }^{1 *}$
}

\begin{abstract}
${ }^{I}$ Department of Psychiatry and Neuropsychology, School for Mental Health and Neuroscience, Maastricht University, The Netherlands; ${ }^{2}$ University Eye Clinic Maastricht, Maastricht University, The Netherlands, ${ }^{3}$ Interdisciplinary Centre for Training in Medical Education (AIXTRA), Medical Faculty, RWTH Aachen University, Germany, ${ }^{4}$ Department of Neuropsychology and Psychopharmacology, Maastricht University, The Netherlands
\end{abstract}

\begin{abstract}
No pharmacological treatment is available to date that shows satisfactory effects on cognitive symptoms in patients diagnosed with schizophrenia. Phosphodiesterase inhibitors (PDE-Is) improve neurotransmitter signaling by interfering in intracellular second messenger cascades. By preventing the breakdown of cAMP and/or cGMP, central neurotransmitter activity is maintained. Different PDE families exist with distinct characteristics among which substrate specificity and regional distribution.
\end{abstract}

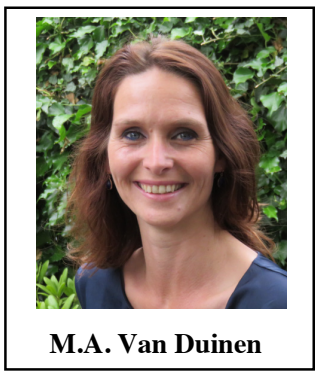

Preclinical data is promising especially with regard to inhibition of PDE2, PDE4, PDE5 and PDE10. In addition, cognitive improvement has been reported in both elderly and/or non-impaired young human subjects after PDE1 or PDE4 inhibition. Moreover, some of these studies show effects on cognitive domains relevant to schizophrenia, in particular memory. The current review incorporates an overview of the distinct molecular characteristics of the different PDE families and their relationship to the neurobiological mechanisms related to cognitive dysfunction in schizophrenia. So far, procognitive effects of only three types of PDE-Is have been assessed in patients diagnosed with schizophrenia inhibiting PDE3, PDE5 and PDE10. However, the limited data available do not allow to draw firm conclusions on the value of PDE-Is as cognitive enhancers in schizophrenia yet. The field is still in its infancy, but nevertheless different PDE-Is seem promising as candidate to optimise neural communication in the prefrontal cortex favouring cognitive functioning in patients diagnosed with schizophrenia, in particular dual inhibitors including PDE1-Is, PDE3-Is and PDE10A-Is.

Keywords: Schizophrenia, phosphodiesterase inhibitor, cognition, memory, pharmacological treatment.

\section{INTRODUCTION}

One century ago, the syndrome now called schizophrenia was referred to as 'dementia praecox'. This implies that back then, cognitive symptoms were acknowledged as a hallmark of the disorder. In the years thereafter, attention shifted towards positive symptomatology. However, during the past twenty years, a renewed interest in cognitive impairment in schizophrenia has evolved. Not only is it recognized as a prominent feature and symptom domain impacting on course and outcome [1-5], cognitive alterations also represent a stable trait, independent of positive symptoms, that precedes the onset of schizophrenia [6-10]. Pharmacological interventions in schizophrenia are targeting positive symptoms, and an effective treatment of cognitive symptoms in patients with a diagnosis of schizophrenia is presently still lacking. Considering the impact of cognitive impairment, and the associated costs, the need for development of pharmacological interventions specifically targeting this domain is undeniable. Despite a strong increase in activity within this field, to date no cognition enhancer is available specifically targeting those cognitive problems that constitute a core feature of schizophrenia.

This review will describe the potential of phosphodiesterase inhibitors (PDE-Is) as cognitive enhancers in schizophrenia. The working mechanism of PDE-Is is intrinsically different from drugs currently in use as antipsychotics. Instead of stimulating or inhibiting receptor activity, PDE-Is affect intracellular second messenger systems downstream of the receptor. Since different neurotransmit-

*Address correspondence to this author at the Department of Psychiatry and Neuropsychology, School for Mental Health and Neuroscience, Maastricht University, 6200 MD Maastricht, The Netherlands; Tel: 003143 3881168; Fax: 003143 3674086; E-mail: jos.prickaerts@maastrichtuniversity.nl ter systems can have similar second messengers [11], the effect of PDE-Is is not limited to a single neurotransmitter system. In addition, due to the distinct spatial organization of the different PDE families and their isoforms, it might be possible to specifically stimulate the activity of neurotransmitter systems in restricted brain areas. This allows targeting those areas that are critically involved in the execution of cognitive tasks. For this reason, PDE-Is might be superior to drugs currently in use for schizophrenia, in particular with regard to treating cognitive symptoms.

\section{COGNITIVE DEFICITS IN SCHIZOPHRENIA}

In schizophrenia, a broad spectrum of cognitive alterations is present in an array of functions $[5,8,10,12]$. Cognitive impairment is present in many patients suffering from schizophrenia and results in significant disabilities in social, occupational and economic functioning [13]. All tested functions are included in the domains of cognitive functions identified by MATRICS (Measurements and Treatment Research to Improve Cognition in Schizophrenia; http://www.matrics.ucla.edu). These domains include attention and vigilance, processing of speed, memory (working memory, verbal learning and memory, visual learning and memory), reasoning and problem solving (executive function), and social cognition.

Cognitive control is known to rely on coordination processes of several brain regions. The most important regions are the dorsolateral prefrontal cortex (DLPFC), medial frontal cortex, including the anterior cingulate cortex (ACC), and parietal regions. Damage to these regions results in deficits in context maintenance and response inhibition. These brain regions interact in a complex network manner to fulfil multiple purposes and act in several different executive processes. The DLPFC maintains rules for action and response selection, parietal regions are important to shift attention 
and focus, and the ACC detects response conflicts and activates the DLPFC to improve performance. In addition, networks including the ACC have also been implicated in social cognition [14]. The frontal lobes are crucial to problem solving, insight and other high level reasoning. In particular, functional consequences of impaired PFC signalling in general, ranges from impaired judgement, organisation, planning and decision-making, to behavioural disinhibition and impaired intellectual abilities, resulting in diminished abilities with regard to coordinational processes [15]. Indeed, perturbations in patients with a diagnosis of schizophrenia result in difficulties in planning and organization. Therefore cognitive control must be seen as the activation of a complex interconnected cortical network [16]. In patients with a diagnosis of schizophrenia, the DLPFC shows task-related reduced activity $[17,18]$. Reduced DLPFC activity results in impaired task performance and behavioural disorganization as well as in impaired prefrontal control mechanisms [16]. In addition, decreased activation of DLPFC and ventrolateral PFC has been related to impaired episodic memory, both encoding and retrieval processes [19]. Episodic memory is required for a wide range of cognitive functions and impairments in schizophrenia have also been associated with structural abnormalities in medial temporal regions, including the hippocampal region which mediates learning and memory formation and the amygdala [20, 21].

Evidence from neuroimaging studies in patients with schizophrenia suggests marked structural changes within the brain that can be related to the cognitive deficits mentioned above. Reduced whole brain volume together with increased volume of the lateral ventricles has been confirmed by a recent meta-analysis [22]. In addition, impairments in cognitive domains may be associated with alterations in grey and white matter density in relevant brain areas $[16,23,24]$. However, the causality of this relationship has been disputed [25]. White matter deficits have been found in the right deep frontal lobe and left deep temporal lobe in first episode patients [26], and seem to occur to a similar degree in medicated and unmedicated patients [27]. A meta-analysis of diffusion tensor imaging studies revealed that the tracts involved suggest a lack of connectivity within the fronto-limbic circuitry [26]. Another recent meta-analysis did not find differences in white matter volume in patients naive to antipsychotic medication [22]. The same authors described a negative correlation between gray matter loss and cumulative exposure to antipsychotic treatment. This is in line with the finding that gray matter deficits are less extensive in medication naive patients [27]. Grey matter loss has been described for frontal, temporal and parietal regions [28]. Meta-analyses have shown pronounced decrease in the insula, caudate, uncus regions and superior temporal gyri [24, 29-31]. Gray matter volume loss in the superior temporal gyri and left insula correlate with the severity of auditory hallucinations, possibly related to disturbed language processing $[24,32]$.

\section{NEUROTRANSMITTER AND RECEPTOR THEORIES OF SCHIZOPHRENIA}

\section{Signal Transduction}

PDE-Is affect neuronal communication by interfering in intracellular second messenger pathways, i.e. pathways activated after extracellular neurotransmitter binding. Neurotransmitter receptors can be divided into groups according to the way in which receptor and effector function are coupled. One group is the ionotropic or ion channel receptors and the other is the metabotropic or GTPbinding protein (G-protein) coupled receptors.

G-protein activation engages second messenger cascades [33]. Second messengers translate an extracellular signal, such as the binding of a neurotransmitter to its receptor, into a non-structural (increased neurotransmitter release) or structural (receptor and/or synapse formation) cellular responses [34, 35]. Traditionally, the cAMP second messenger system (Gs and Gi linked) and the phos- phoinositol second messenger system (Gq linked) received the most attention. The second messenger complex inositol-1, 4, 5, triphosphate/diacylglycerol $\left(\mathrm{IP}_{3} / \mathrm{DAG}\right)$ is formed out of the hydrolysis of phosphatidylinositol 4, 5-biphosphate $\left(\mathrm{PIP}_{2}\right)$ by phospholipase $\mathrm{C}$ (PLC) after activation by Gq. The second messenger cAMP is synthesised by adenylate cyclase (AC), which is stimulated or inhibited by Gs or Gi, respectively, and degraded by different phosphodiesterases (PDEs)

cAMP activates cAMP-dependent protein kinase (PKA), which phosphorylates cAMP response element binding protein (CREB). $\mathrm{P}-\mathrm{CREB}$ is an activated transcription factor, which initiates transcription of specific genes which can include neurotransmitter receptors such as ionotropic AMPA receptors or growth factors as brain-derived neurotrophic factor (BDNF) [36]. DAG activates calcium-dependent protein kinase (PKC) in the presence of calcium $\left(\mathrm{Ca}^{2+}\right)$, which is mobilized by $\mathrm{IP}_{3}$. PKC activates CREB via the MAP kinase pathway.

Postsynaptic $\mathrm{Ca}^{2+}$, either after mobilization by $\mathrm{IP}_{3}$ or after entering via the ionotropic NMDA receptor, can also bind to calmodulin. This so-called $\mathrm{Ca}^{2+} / \mathrm{CaM}$ complex activates $\mathrm{Ca}^{2+} / \mathrm{CaM}$ protein kinase $(\mathrm{CaMK})$, which can stimulate the insertion of AMPA receptors in the postsynaptic membrane [37]. In addition, CaMK can activate PKC, but also PKA via activation of $\mathrm{AC}$ and subsequent production of cAMP. On the other hand, PKA can also activate the MAP kinase pathway. Thus, there is interplay between the cAMP second messenger system and the phosphoinositol second messenger system.

The enzyme AC is also present presynaptically and elevation of cAMP has been found to result in the synthesis and/or release of several neurotransmitters including glutamate and dopamine (DA) [38-40]. This might be mediated via a presynaptic CaMK/cAMP/ PKA cascade and hence signal transduction is influenced.

$\mathrm{Ca}^{2+}$ is also known to activate the enzyme nitric oxide synthase (NOS) which produces NO [41]. The latter stimulates the enzyme guanylate cyclase (GC) which produces the second messenger cGMP, which is also degraded by PDEs. cGMP activates cGMPdependent protein kinase (PKG), which can also induce CREB phosphorylation [42]. NO is also known to act as a retrograde messenger and can thus stimulate presynaptic GC. Linked to this, via a cGMP/PKG cascade the synthesis and/or release of neurotransmitters including glutamate and DA can be influenced [43, 44], and thus signal transduction. Fig. 1 provides a schematic overview of the pre- and postsynaptic cellular processes related to the second messengers cAMP and cGMP involved in signal transduction.

Different neurotransmitter systems have been suggested to be involved in the pathogenesis of schizophrenia, including DA, glutamate, $\gamma$-Aminobutyric acid (GABA), serotonin (5-HT), and acetylcholine. All of these systems may be potential targets to, directly or indirectly, ameliorate cognitive functioning in schizophrenia. As described above, the cascade of intracellular events that follows neurotransmitter binding depends on the type of receptor being stimulated. Since PDE-Is potentiate neurotransmitter signalling by interfering within intracellular cascades, a brief overview is given on the supposed role of the different neurotransmitter systems in schizophrenia. This provides the framework from which more specific targets for treatment of cognitive deficits in schizophrenia can be inferred.

\section{Dopamine}

Historically, the dopaminergic theory of schizophrenia received most attention. In essence, hyperactivity of the dopaminergic system was supposed to be the primary cause of this disorder [45]. Later, this theory was refined and hyperactivity was proposed to be confined to the mesolimbic areas [46]. 


\section{presynapse $\longrightarrow$ postsynapse}

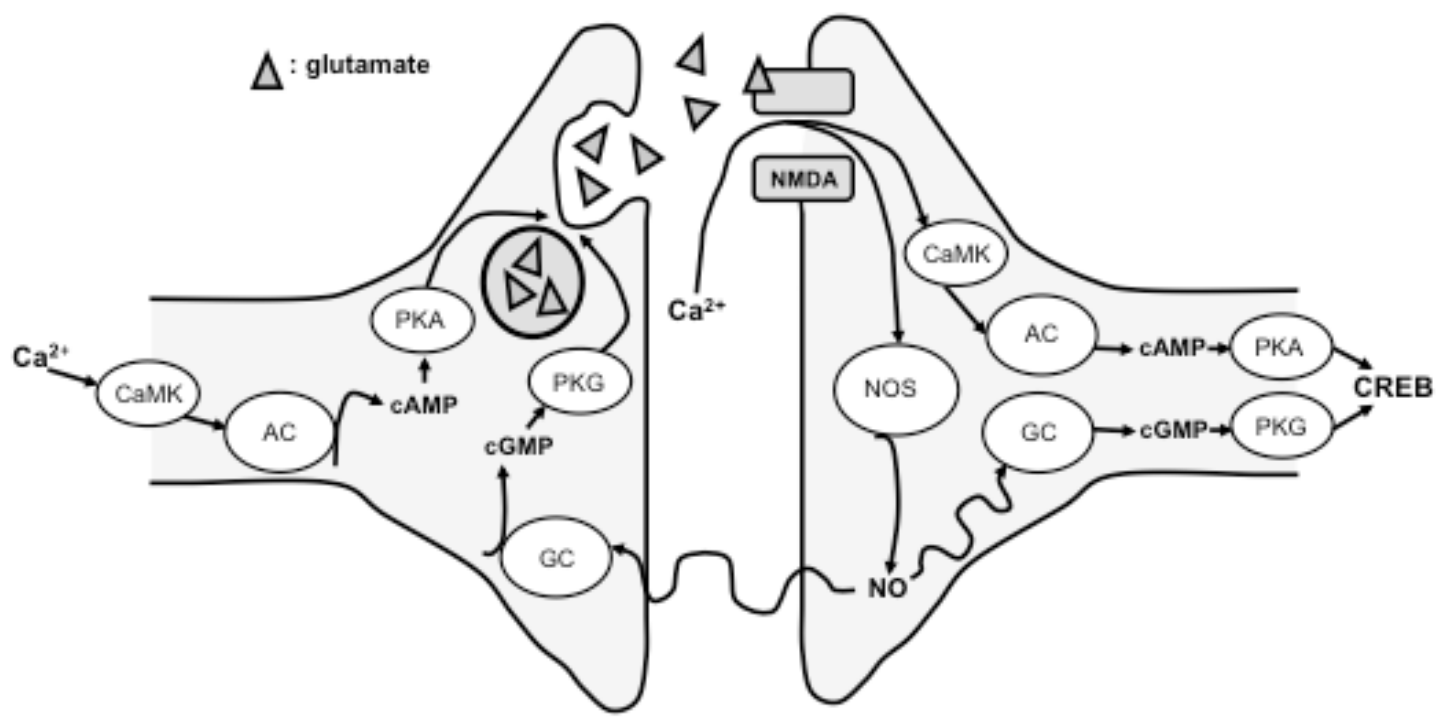

Fig. (1). $\mathrm{Ca}^{2+}$ entry through the postsynaptic ionotropic glutamatergic NMDA receptor results in the activation of CaMK. Activated CaMK stimulates the insertion into the membrane of the ionotropic AMPA receptor which is involved in baseline signal transduction. In addition, CaMK activates AC resulting in the production of the second messenger cAMP. The latter activates PKA, which has a positive effect on the transcription factor CREB. CREB activation is known to result in an increased gene expression, including the genes for AMPA receptors and brain BDNF and thus future signal transduction is enhanced. $\mathrm{Ca}^{2+}$ is also known to activate NOS, which produces NO. The latter can activate GC, which produces the second messenger cGMP. Postsynaptically cGMP has similar effects as cAMP, but via activation of PKG. NO is also known to act as a retrograde messenger and can thus stimulate presynaptic GC. It has been found that cGMP stimulates the synthesis and/or release of glutamate and DA via PKG. Presynaptic AC produces cAMP which is known to increase the synthesis and/or release of glutamate and DA. This is likely mediated via a CaMK/cAMP/PKA cascade.

DA exerts its function by different central pathways and different receptor subtypes. The mesolimbic and mesocortical pathway are critically involved in the pathogenesis of schizophrenia [47, 48]. Both pathways arise from the ventral tegmental area. The mesolimbic pathway projects to the ventral striatum (the nucleus accumbens) and the amygdala. The mesocortical pathway projects to cortex including the medial and prefrontal cortex, the cingulate and the enthorinal cortex. In addition, five DA receptor subtypes have been identified $\left(\mathrm{D}_{1-5}\right)$, of which both pre-synaptic and post-synaptic receptors may play a role in schizophrenia. In particular D1 and D2 receptors have been described in the dopaminergic theory of schizophrenia [49]. D1 receptors are most widely distributed throughout the brain as compared to the other dopaminergic receptors. In the nucleus accumbens the D1 receptor is situated postsynaptically, whereas the D2 receptor is situated both pre- and postsynaptically. Overstimulation of the postsynaptic D2 receptors in the nucleus accumbens is thought to contribute to the positive symptoms of schizophrenia $[48,50]$.

In the PFC, the D1 receptor is situated post-synaptically (Gscoupled) as well, but other than in the nucleus accumbens, D2 receptors are located pre-synaptically (Gi-coupled) only. The impact of negative feedback on signal transduction by pre-synaptic D2 stimulation is probably limited, since D2 numbers within the PFC are low. It has been suggested that pre-synaptic D3 receptors, which have functional and pharmacological similarities to D2 receptors, are the primary pre-synaptic target for DA in this area. Under normal circumstances, DA modulates the excitability of glutamatergic and GABA-ergic neurons. DA stabilizes cortical network activity by decreasing the level of cortical noise and as such, enhancing cortical signal-to-noise ratio [48].
Negative and cognitive symptoms of schizophrenia, are associated with reduced DA function in the PFC, also referred to as hypofrontality. The reduced prefrontal DA function disturbs the balance of excitatory-inhibitory synaptic interactions in this area [51].Thus, the decreased ratio of D1/D2 signalling in schizophrenia would favour unstable cortical representation of internal and external stimuli [52] and as such, affect cognition.

\section{Glutamate}

A second major theory of schizophrenia concerns glutamatergic neurotransmission. An early report by Kim et al. (1980; [53]) showed low CSF glutamate levels in patients with a diagnosis of schizophrenia, suggestive of a hypofunctional glutamatergic system. Further indication came from the observation that psychotic symptoms could be evoked in healthy individuals by antagonising the NMDA receptor, one of the ionotropic (calcium channel) glutamate receptors, using ketamine and phencyclidine $[54,55]$. Subsequent clinical evidence pointed to dysfunctional receptors as an important mediator of reduced glutamatergic functioning. Postmortem brain tissue from patients with a diagnosis of schizophrenia showed an altered expression of NMDA receptor subunits, primarily in the PFC [56]. This theory is referred to as the NMDA Receptor Hypofunction Hypothesis. The shift in subunits of the NMDA receptors in GABAergic interneurons results in diminished NMDA activity leading to reduced GABAergic tone on other GABAergic interneurons which synapse on the dopaminergic mesocortical pathway neurons [57]. The increased inhibition of the GABAergic interneurons results in hypofrontality. In other words, the observed abnormalities in DA signalling as described in the dopaminergic theory of schizophrenia, might be secondary to NMDA dysfunction. 


\section{GABA}

In addition to a reduced GABAergic tone due to NMDA receptor hypofunction, primary abnormalities in this major inhibitory neurotransmitter system, in particular within the DLPFC, have been reported in schizophrenia. Both the synthesis and reuptake of GABA may be significantly reduced in a subset of DLPFC inhibitory neurons [58]. The reduced synthesis can be ascribed to locally reduced mRNA levels encoding glutamic acid decarboxylase, an enzyme that synthesizes GABA in about $30 \%$ of the GABAergic neurons in this area [59-61]. Moreover, a negative relationship has been described for glutamic acid decarboxylase mRNA and GABA membrane transporter expression in post-mortem material from patients with a diagnosis of schizophrenia [62]. This could well represent a compensatory mechanism, which makes it difficult to assess the magnitude of the alterations within the GABAergic system as a whole.

\section{Serotonin}

There is no established theory on the involvement of 5-HT in the pathophysiology of schizophrenia, but some observations suggest alterations within the serotonergic system. To draw conclusions on whether the serotonergic system is primarily involved in the pathophysiological mechanisms of schizophrenia is complicated by effects directly induced by medication use or related to comorbid conditions [63]. Especially in the case of post-mortem material, statements on the serotonergic status of patients with a diagnosis of schizophrenia who committed suicide are complicated due to the described relation between suicide and altered 5-HT homeostasis [64]. Most evidence in support of pro-cognitive effects induced by serotonergic manipulation comes from the comparison of typical and atypical antipsychotics. The last target the DA system, especially the D2 receptor, but as opposed to the classical typical antipsychotics, there is an additional, often stronger, effect on the serotonergic system. With regard to improving cognitive symptoms, atypical antipsychotics have shown their superiority as compared to the conventional antipsychotics, which has been ascribed to the antagonism of the 5HT2A receptor (Gq-coupled, postsynaptically) which is thought to induce the release of glutamate in the PFC [65, 66], although the exact mechanism for this increase is not clear [67]. Moreover, stimulation of a second 5-HT receptor subtype, the 5HT1A receptor, has been proposed as favourable target to specifically target cognitive problems related to schizophrenia [68]. Some atypical antipsychotics, like clozapine and quetiapine, are partial $5 \mathrm{HT} 1 \mathrm{~A}$ agonists. It has been suggested that post-synaptic $5 \mathrm{HT} 1 \mathrm{~A}$ agonism (Gi/0-coupled) stimulates DA release in the PFC, and that simultaneous 5HT2A blockade strengthens this effect [69].

\section{Acetylcholine}

Theories on the role of cholinergic alterations in schizophrenia are less common, but considering the role of acetylcholine (ACh) in cognition, the cholinergic system should not be neglected as a potential target of cognition enhancement in schizophrenia. In fact, preventing the hydrolysis of ACh by giving acetylcholinesterase inhibitors as adjunctive therapy in patients with a diagnosis of schizophrenia, improved memory, motor speed and the attentional aspect of executive function [70]. The acetylcholinesterase inhibitor rivastigmine specifically recovered cognitive impairments in the NMDA antagonist ketamine-treated rats [71]. In other words, stimulating ACh signalling partly attenuates NMDA receptor antagonism.

Low binding to muscarinic postsynaptic (Gs-coupled) M1 and modulatory postsynaptic M4 (Gs-coupled) receptors in the PFC of patients with a diagnosis of schizophrenia has been found [72]. This suggests that ACh might directly modulate cortical DA release [73]. Also a decrease in presynaptic (sodium and calcium channel) nicotinic alpha7 receptors in the PFC of patients with a diagnosis of schizophrenia has been found [72]. As significant numbers of nico- tinic receptors, in particular alpha7 and alpha4beta 2 receptors are found on axon terminals, this suggests again a role in the modulation of neurotransmitter release $[74,75]$. For instance, within the hippocampus, nicotine receptors may modulate the release of a number of neurotransmitters besides DA, including glutamate, GABA, noradrenalin, and ACh [76]. In the midbrain, nicotine receptors lie directly on DA neurons, modulating their firing rate and thereby, DA release in forebrain structures [77]. In rats, the presence of functional muscarinic receptors has been detected on dopaminergic neurons in the substantia nigra and ventral tegmental area [78]. Along similar lines, stimulation with muscarinic M1 agonists decreased DA release, while M2 antagonists stimulated DA release in the dorsal striatum respectively [79]. This is explained by their action on presynaptic inhibitor autoreceptors which are normally stimulated via M1 (Gq coupled) and inhibited via M2 (Gi coupled).

Indeed, in vitro and in vivo rat experiments showed that both alpha4beta2 and alpha7 nicotinic receptors can modulate DA release in the PFC [80]. Mice experiments showed that prefrontal alpha4beta 2 and alpha7 nicotinic receptors are involved in the control of glutamatergic signalling [81]. Along similar lines, rodent studies showed that both nicotinic receptors are indeed involved in $\mathrm{PFC}$ related functions, i.e. attention, executive function and working memory [82]. Consequence, alpha7 receptor agonists are currently being developed as to enhance cognitive function in schizophrenia [83].

\section{SIGNAL TRANSDUCTION AND IMPROVEMENT OF COGNITIVE FUNCTION IN SCHIZOPHRENIA}

Although many different neurotransmitters appear to be involved in the observed 'hypofrontality' of the prefrontal cortex, it is clear that eventually the action of D1 receptors should be enhanced to attenuate cognitive impairment. This can be accomplished by increasing DA release in the PFC and/or to enhance downstream events that follow DA receptor binding. Fig. 2 illustrates how glutamate is mediating DA release in the PFC and which downstream second messenger signalling cascades are involved.

D1 receptors are stimulatory Gs coupled receptors which activate $\mathrm{AC}$ resulting in the increased synthesis of cAMP (Fig. 2). The action of cAMP and its related cellular response is terminated by specific PDEs, i.e. intracellular enzymes that degrade cAMP and/or cGMP. PDEs have been classified into 11 families (PDE1-PDE11) based on several criteria such as subcellular distributions, mechanisms of regulation, and enzymatic and kinetic properties. Most of these families have more than one gene product (e.g., PDE4A, PDE4B, PDE4C, PDE4D). In addition, each gene product may have multiple splice isoform variants (e.g., PDE4D1-PDE4D9). In total there are more than 100 specific PDEs [11].

Specific PDEs can be inhibited with selective PDE-Is. PDE-Is selective for PDEs that degrade cAMP could have potential as cognition enhancing drugs for schizophrenia as they stimulate the PFC D1 receptor-linked cAMP/PKA signalling cascade [84]. Interestingly, in contrast to the approved pro-cognitive drugs including acetylcholinesterase inhibitors, PDE-Is do not target a single neurotransmitter system since they exert their effects on the level of intracellular second messenger cascades that are shared by various transmitter systems. As a result, multiple neurotransmitter systems can be influenced, which might be preferable since optimal cognitive function relies on the action of different neurotransmitters [85, 86]. Of note, cAMP/PKA signalling is also important in the striatum in both direct and indirect pathway interneurons, with a preference for the latter $[87,88]$. It is assumed that PDE-Is that act predominantly in indirect pathway GABAergic interneurons should work like DA D2 receptor antagonists and decrease in particular the positive symptoms. In detail, D2 receptors are inhibitory Gicoupled receptors which decrease cAMP signalling in the indirect pathway. D2 receptor antagonists as well as cAMP-specific PDE-Is increase cAMP signalling. 


\section{presynaptic $\longrightarrow$ postsynaptic}

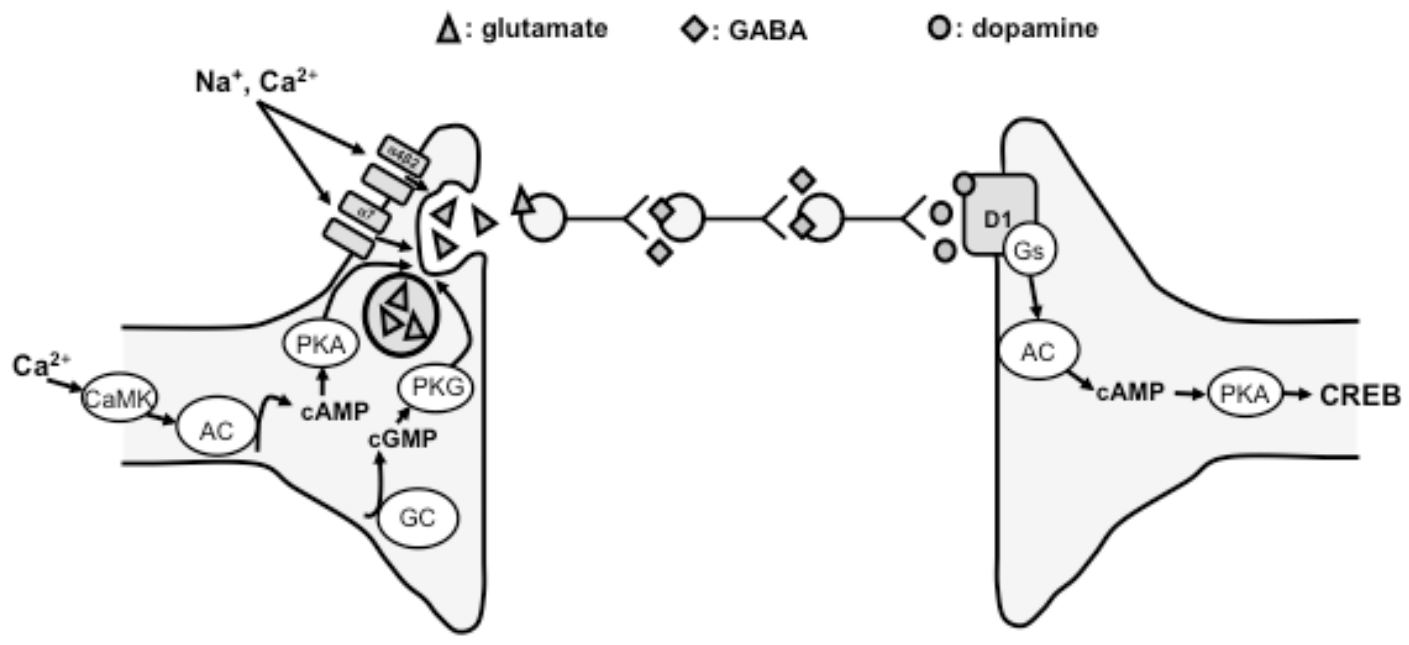

Fig. (2). Intracellular signalling cascades mediating D1 receptor signalling that could be involved in PFC cognitive function. Glutamate release is mediated presynaptically via a cAMP/PKA as well as cGMP/PKG cascade (see also Fig. 1). Glutamate binds to the NMDA receptor on GABAergic interneurons which inhibit GABAergic interneurons synapsing on dopaminergic neurons. The latter release DA which, after binding to the D1 receptor, stimulate the cAMP/PKA/CREB pathway. Of note, glutamate release and DA release itself are also controlled by alpha4beta2 and alpha7 nicotinic receptors. Furthermore, metabotropic receptors for ACh (M1 and M4) or 5-HT (5-HT1A and 2-HT2A) can modulate DA release in the PFC although the exact mechanism of action is not clear. (D1: DA type 1; PFC: prefrontal cortex; GC: guanylyl cyclase; AC: Adenylyl cyclase; PKA: phosphokinase A; NMDA: $N$-Methyl-D-aspartate; GABA: $\gamma$-Aminobutyric acid; CREB: cyclic AMP response element-binding protein; M1: muscarinic type 1 receptor)

Glutamate can also bind to G-protein (both Gs and Gi) coupled metabotropic receptors, but the ionotropic NMDA receptor is involved in dopaminergic cognitive function in the PFC. The release of glutamate itself can be stimulated by a presynaptic cAMP/PKA as well as cGMP/PKG cascade (Fig. 2). Inhibition of presynaptic cAMP- and/or cGMP-specific PDEs could therefore also have potential to improve cognitive function in schizophrenia.

\section{PHOSPHODIESTERASE INHIBITION AND COGNITIVE IMPROVEMENT RELATED TO SCHIZOPHRENIA}

Despite the recognition of the strong negative impact of cognitive symptoms in schizophrenia, and the proven pro-cognitive effects of PDE-Is in animals, there have been only few clinical trials testing the efficacy of PDE-Is in patients with schizophrenia [8991]. Cognitive effects of PDE-Is mainly have been described in animal models not related to schizophrenia [92]. Generally, reliable modelling of cognitive deficits related to schizophrenia in animals has proven difficult. However, the use of NMDA antagonists, such as phenylcyclohexylpiperidine (PCP), MK-801 and ketamine, may be valid models with regard to the underlying neurobiological mechanism [93]. Moreover, the behavioural effects partly mimic the deficits as seen in schizophrenia, including some of the cognitive symptoms [94, 95].

Based on the current knowledge of the underlying mechanisms of cognitive impairment in schizophrenia, combined with knowledge on the localization of the different PDE's, assumptions can be made on the efficacy of PDE-Is in the treatment of cognitive deficits in patients with a diagnosis of schizophrenia (Table 1). The following paragraph describes relevant study outcomes in this respect for all PDE families with the exception of PDE6, since this specific family is highly expressed in the photoreceptors of the mammalian retina and not throughout the brain.

\section{PDE1}

PDE1 is a dual inhibitor, orchestrating the activity of both cAMP and cGMP [11]. The mechanism of PDE1 differs from other
PDEs in that it is the only PDE that is calcium/calmodulindependent. Optimal activity of PDE1 requires the binding of calcium ions. Consequently, PDE1 is a key enzyme in the complex interaction between the second messenger systems relying on cAMP on the one hand, and $\mathrm{Ca}^{2+}$ on the other hand. As a consequence, PDE1 inhibitors (PDE1-Is) have little effect on cyclic nucleotide levels in the resting state. They enhance cyclic nucleotide signalling in neurons under conditions that are associated with increased intracellular calcium levels, among which learning.

Within the CNS, PDE1 is present in the neocortex and the hippocampus [96, 97]. Moreover, the abundant expression of PDE1 in specific subsets of neurons in the striatum suggests it may correlate with cells having dopaminergic innervation and/or high levels of neuronal integration [96]. The PDE1-I vinpocetine was discovered in the late 1960's and has been used both in animal models and in humans for different indications. This PDE1-I finds it origin in the periwinkle plant, and as such, it is commonly referred to as herbal medicine. In rats, chronic treatment with vinpocetine improved streptozotocin-induced learning impairment and memory decline in Morris Water Maze and passive avoidance paradigms [98]. The authors suggested that the effect could partly be explained by the normalization of cholinergic function by inhibiting acetylcholinesterase activity. Whether the prevention of cAMP and cGMP breakdown contributes to this positive effect needs further research.

The pharmaceutical industry shows interest in PDE1-I as a specific treatment of cognitive symptoms in schizophrenia [99], but we found no evidence of initiation of clinical trials yet. The PDE1-I vinpocetine has been applied for cognitive symptoms related to other disorders, mainly dementia. Studies have been performed using vinpocetine in cognitive impairment and dementia with mixed results, not supportive for clinical application [100]. Nevertheless, a number of studies showed benefit of this compound in different disorders characterized by cognitive problems, including Mild Cognitive Impairment [101], organic psychosyndromes [102], elderly with chronic cerebral dysfunction [103] and in healthy female volunteers [104]. A more recent phase IV trial with Cognitex, 
Table 1. PDE characteristics relevant for therapeutic use in schizophrenia. $F C=$ frontal cortex

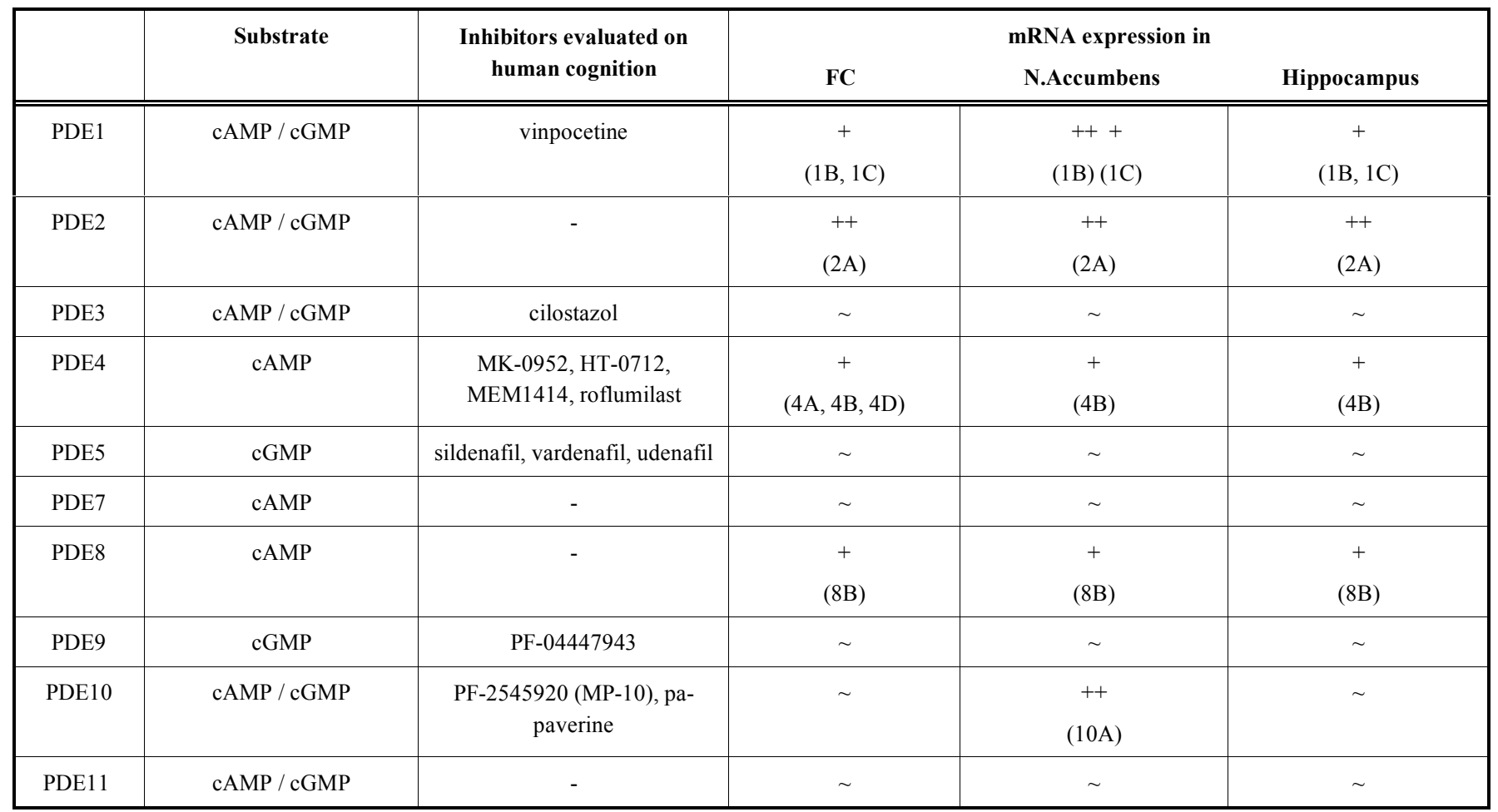

Relative expression values normalized with GPS1, RPOL2 and PSMB2 as reference genes, based on Lakics et al., 2010 [109]. ++: 100\%, +: 20-40\%, : $20 \%$

a dietary supplement including vinpocetine, was initiated. Cognitex significantly improved memory function in elderly with reported memory impairment [105]. However, this study was uncontrolled and Cognitex contains other ingredients that could have influenced memory function, which makes it hard to draw any conclusions on the specific effects of the PDE1-I. In Alzheimer's disease (AD), vinpocetine showed no cognitive improvement in an early openlabel pilot study [106].

In addition to its function as PDE1-I, vinpocetine is a potent vasodilator, with strongest effect in the brain, which could potentially potentiate its suggested effects on memory [107]. Whether PDE1-Is can directly improve memory function in schizophrenia, and whether it will positively affect other cognitive symptoms within this syndrome, still needs to be investigated.

\section{PDE2}

PDE2 is part of the dual substrate PDE family, which shows affinity for both cAMP and cGMP, and is cGMP stimulated [11]. It has been demonstrated that PDE2 is observed in various brain regions including the hippocampus, cortex, nucleus accumbens and caudate putamen in healthy adults, people suffering from $\mathrm{AD}$ and age-matched controls $[108,109]$. PDE2 mRNA is most prevalent of all PDEs in human hippocampus and all cortical regions, i.e. frontal, parietal, and temporal cortex

With regard to cognitive effects, the most widely used PDE2-I is BAY 60-7550, but there are also other, less specific, inhibitors e.g. exisulind (Aptosyn). In addition to PDE2 inhibition, the latter also inhibits PDE5. Aptosyn has been used in clinical trials in the field of oncology. To our knowledge, cognitive parameters were not included in these trials.

Interestingly, several studies have shown that PDE2 inhibition with BAY 60-7550 reverses memory deficits induced by the NMDA receptor antagonist MK-801 as shown in the T-maze continuous alternation and the object recognition task $[110,111]$. The
MK-801-induced memory deficit model is a commonly used model for preclinical research and disrupts particularly short-term memory and attention processes, thereby causing cognitive deficits affiliated to schizophrenia. Furthermore, positive effects of PDE2 inhibition on cognition have also been found in another animal model known to induce deficits related to schizophrenia: (sub)chronic PCP administration [112]. More specifically, BAY 60-7550 reversed PCPinduced attention deficits in the attention shifting task. Additionally, it has recently been found that BAY 60-7550 can affect specific early information processing in rats [113].

More generally, it has been shown that BAY 60-7550 improved memory function in a variety of tasks in healthy rodents as well as in animals impaired by pharmacological or transgenic intervention (e.g. [114-116]). These findings suggest that PDE2 might be a potential therapeutic route to treat the cognitive deficits in people suffering from schizophrenia, especially since PDE2 is widely available in the relevant areas in the human brain including the frontal cortex, nucleus accumbens and hippocampus.

\section{PDE3}

Type 3 PDE-Is are dual inhibitors, preventing the break-down of both cAMP and cGMP. The effects of the PDE3-I cilostazol on cognition, have been assessed in patients with schizophrenia [90]. This clinical study was an open-label pilot study, describing the results of 6 patients. Patients were stable on second generation neuroleptics, combined with biperiden and in most cases, a benzodiazepine. Patients were treated for 8 weeks with cilostazol; 2 weeks $25 \mathrm{mg} / \mathrm{d}$, and 6 weeks $50 \mathrm{mg} / \mathrm{d}$. Six cognitive tasks assessing prefrontal functioning were performed and one memory task. The score on the Trial Making Test showed a significant decrease after 8 weeks of cilostazol treatment as compared to baseline values. This suggests improved visuo-motor search skills, simple attention and processing speed. Some of these cognitive functions were included in other tasks as well, in which no significant improvement was found. Of note, the patients were on drugs that are known to 
have pro-cognitive effects. Since the PDE3-I promotes the effects of neurotransmitter systems affected by the drugs the patients were receiving, it might be possible that the resulting improvement is an interaction effect. On the other hand, in advance of the possible use of PDE-Is in the treatment of cognitive symptoms in schizophrenia, it is realistic to assume that PDE-Is will be used as add-on therapy in real-life as well.

In $\mathrm{AD}$, three clinical trials have been performed with cilostazol. Sakurai et al. (2013; [117]) describe a sample of 11 patients with mild to moderate $\mathrm{AD}$ and cerebrovascular disease who received cilostazol $100 \mu \mathrm{g}$ for six months. Whereas the control group of AD patients on clopidogrel or aspirin showed cognitive decline over this period, the cilostazol treated subjects did not. This might indicate that cilostazol prevents $\mathrm{AD}$ progression. In addition to stable cognitive performance, cilostazol increased regional cerebral blood flow in the right anterior cingulate lobe. Hence, its effects on cognition might be the result of both PDE inhibition and increased supply of oxygen and brain specific nutrients. The cerebral blood flow increasing ability of cilostazol in humans has been confirmed before in different studies in chronically treated patient groups [118, 119]. Remarkably, this effect was not found in acute treatment in healthy volunteers [120], which suggests that longer term treatment is necessary to exert effects on cerebral blood flow.

A similar study had been initiated in 2011 by the Seoul National University Hospital (Lee (personal communication); ClinicalTrials.gov identifier: NCT01409564). A total number of 36 mild to moderate $\mathrm{AD}$ patients treated with donepezil was included in this trial. Subjects were equally divided over a cilostazol (100 mg BID) group and placebo group for 24 weeks. However, no difference between groups was found for cognitive measures which included the Mini-Mental State Exam (MMSE) and the cognitive scale of the cognitive portion of the Alzheimer's Disease Assessment Scale.

In a first pilot trial of Arai et al. (2009; [121]), 10 mild to moderate $\mathrm{AD}$ patients received $100 \mathrm{mg}$ /day cilostazol as add-on to donepezil ( $5 \mathrm{mg} /$ day) for a variable period of time, ranging between 1 and 13 months. This study was an open-label, uncontrolled trial. In this small group, a statistically significant improvement on the MMSE was reported during the first six months of follow up.

Taken together, the conflicting results of the AD studies do not allow drawing a clear conclusion on possible cognition enhancing effects of PDE3 inhibition yet. The results of PDE3-I treatment has also been tested on cognitive function in patients with a diagnosis of schizophrenia on antipsychotic treatment. However, its results were not uniform enough to be conclusive yet. More research is needed on PDE3 inhibition and its possible cognition enhancing effects in general and schizophrenia in particular.

\section{PDE4}

Different PDE4 inhibitors (PDE4-Is) are available for clinical use and have been tested in both humans and animals on procognitive abilities. However, the focus has been in particular on memory and to our knowledge, there are no clinical trials with PDE4-Is in patients with schizophrenia. Concerning the localization of PDE4, PDE4-Is can provoke their effects in a large number of brain areas, including the cortex, striatum and hippocampus. In these areas mRNA of three of the four isoforms (PDE4A, B and D) have been shown to be present in the human brain [109].

Despite the absence of reports on the relationship between PDE4-I and cognitive symptoms in schizophrenia, PDE4 has been linked to schizophrenia. Different genetic studies have shown a positive relationship between PDE4B polymorphisms and schizophrenia, which seem to result in significantly decreased PDE4B levels as detected in postmortem brain tissue [122, 123]. Since PDE4 selectively degrades cAMP, cGMP levels are not affected [11]. In addition, low PDE4B levels do not necessarily result in increased cAMP levels. Several compensatory mechanisms can be activated that counteract the decreased degradation of cAMP by PDE4B. Therefore, the functional meaning of this polymorphism remains to be elucidated.

In rats, PDE4A mRNA showed more than a twofold expressional change in response to PCP. Following, the same authors found significant associations between the occurrence of schizophrenia and single nucleotide polymorphisms in PDE4A [124]. However, since those polymorphisms do not directly influence gene expression, its functional meaning, again, is unclear. Administration of rolipram, a selective PDE4-I, in rats treated with PCP significantly improved the selective impairment on extradimensional shift performance in an extradimensional-intradimensional test of cognitive flexibility [112].

A third genetic link is related to the gene Disrupted-in Schizophrenia-1 (DISC1). A chromosomal translocation disrupts this gene and increases susceptibility for major psychiatric disorders, including schizophrenia $[125,126]$. Moreover, it has been linked to decreased cognitive functioning. HEP3, a haplotype of DISC1, was associated with decreased short-term visual memory in affected offspring of patients with schizophrenia and attention was decreased in both affected and unaffected offspring [127].

All PDE4 isoforms, A-D, directly bind to DISC1 which acts as a molecular scaffold that integrates the cAMP modulatory activity of PDE4 [128]. Mutations both in DISC1 and in particular in the PDE4B gene have been found to potentially alter the interactions within this co-complex. Loss of function of DISC1 increases PDE4D transcription [129], which should negatively impact cAMP levels. Moreover, in mice brain it was discovered that D1 receptor stimulation increased PDE4D9, indirectly regulated by DISC1. It was suggested that this pathway acts as a feedback mechanisms to control dopaminergic signalling [129]. Thus, considering the specific subcellular locations of DISC1 and the PDE4 isoforms, impaired DISC-PDE4 interactions result in dysregulated cAMP signalling in specific cellular compartments as has been found in the mitochondrion [128, 130].

In contrast to the absence of studies that focus on the procognitive effects of PDE4-Is in schizophrenia, different studies have been initiated in the past few years that investigate the cognitive effects of PDE4-Is in AD and related disorders. However, the status and outcomes of these studies including MK-0952 and MEM1414 remain unclear. Another PDE4-I named HT-0712 was tested in a 28-day Phase 2a study including 56 subjects with ageassociated memory impairment. No formal peer-reviewed publication is available, but the compound was reported to have no effects on measures of short-term memory and a statistically significant $15 \%$ increase on long-term memory as assessed with a word learning task (www.dartneuroscience.com). Recently, a follow-up Phase 2 study has started to test again the effects of HT-0712 on ageassociated memory impairment (ClinicalTrials.gov identifier: NCT02013310). In depression, another compound, ND1251, was reported to improve memory in a group of 8 subjects (http://www.outsourcing-pharma.com/Preclinical-Research/PDE4re-emerges-as-depression-therapy). Again, no details on methodology are available to the scientific community.

In the field of dementia, studies have been performed in larger groups. Denbufylline is a xanthine derivate with PDE4 inhibitory activity [131]. In total, 336 patients with different types of dementia received denbufylline for 16 weeks [132]. Patients were divided over three dosage groups; 25,50 or $100 \mathrm{mg}$ twice a day, in addition to a placebo group. Every four weeks patients performed a cognitive battery consisting of the MMSE, digit symbol substitution subtests of the Wechsler Adult Intelligence Scale, and the vocabulary subtest of this scale. Patients on denbufylline showed a 3\% increase on the MMSE, which was statistically different from the $4 \%$ decrease in the placebo group. However, the clinical meaning of the increase needs to be determined. 
Saletu et al. (1992; [133]) performed a study in which 96 mildly to moderately demented patients were assigned to either denbufylline (100 mg BID) or placebo treatment for a period of 12 weeks. In addition, electrophysiological correlates were included. Assessments included Clinical Global Impression, the Mini-Mental State [134], the SCAG [135], the Digit-Symbol Substitution Test [136], and secondary target variables: the Trail-Making Test [137] and the Digit Span Test [136]. In both groups, patients showed treatment induced improvements on all tasks, with significantly stronger increases in the denbufylline group as compared to the placebo group. Clinical Global Impression was reduced with one point in the denbufylline group, based on which the authors concluded that the denbufylline induced changes were clinically relevant.

In sum, PDE4 seems to be a promising target for cognitive improvement, in particular memory improvement. More detailed knowledge of the functional meaning of the different genetic variation as found in schizophrenia in relationship to PDE4 functioning is needed, but the findings reported so far may be reasonably solid. This potentially offers a starting point for investigations into the possible positive effects of PDE4-Is in schizophrenia.

\section{PDE5}

In contrast to the previous PDEs, PDE5 is cGMP specific [11]. PDE5 mRNA has been detected in Purkinje cells and - to a limited amount - in the hippocampus, cortex and dentate gyrus in rodents and healthy adults, but its expression is questionable in the brains of people suffering from AD and age-matched controls [108, 109] which limits the translational value of results from this cognitively impaired group, as well as the possibility to treat older patients with this group of drugs.

Different PDE5-Is are available for clinical use and include among others sildenafil, vardanafil, tadalafil, udenafil and avanafil. The PDE-5 inhibitor sildenafil, marketed under the name Viagra [138], is the most evaluated PDE-I in schizophrenia. Focus was on improving erectile dysfunction (ED), related to antipsychotic medication use. Since Prickaerts et al. [139] showed that PDE5 inhibition can also enhance memory function in rats, research shifted towards the potential of PDE5-Is as cognition enhancers (for a review see [92]). It has been demonstrated that PDE5 inhibition can improve memory, learning and executive functioning in unimpaired as well as impaired rodents. Two animal studies showed procognitive effects of PDE5-Is in models affiliated to schizophrenia, i.e. PCP and MK-801, using the extradimensional-intradimensional (ED/ID) test of cognitive flexibility and an object recognition task respectively $[112,140]$. Of note, the PDE5-I UK-343,664 which failed to penetrate the blood brain barrier, could not prevent MK801 induced memory disruption [140]. These promising results in rodents were preceded by positive effects of the PDE5-I sildenafil on executive functioning in a prefrontal task in cynomolgus macaques [141].

Two studies have been performed in patients with schizophrenia that describe the effect on cognitive parameters. Goff et al. [89] demonstrated that acute add-on treatment with sildenafil 50 and 100 $\mathrm{mg}$, did not affect cognition and positive or negative symptoms in 17 patients suffering from schizophrenia. The effects of sildenafil on five cognitive domains were assessed immediately and during a $48 \mathrm{~h}$ delayed recall, using a verbal learning task, letter-number sequencing, digit symbol, category fluency, continuous performance, and spatial span.

In contrast to the absence of positive effects in response to acute treatment with sildenafil, a study in which this drug was administered chronically did find a positive effect. Akhondzadeh et al. (2011) demonstrated that chronic administration of sildenafil as augmentation therapy to risperidone treatment further reduced negative symptoms in people suffering from schizophrenia. Cognitive measures were not included in this study. However, considering the similarity in dysfunctional pathways as described for cogni- tive and negative symptoms, pro-cognitive effects can be expected to coincide with improvement of negative symptoms.

In healthy adults, acute administration of sildenafil has also shown not to affect the behavioural performance on cognitive tasks. However, some effects on late phase Event-Related Potentials were found [142-144]. These effects could be explained as enhanced ability to focus attention, and select relevant target stimuli that would become apparent under demanding situations [143].

Low-dose treatment with the PDE5-I udenafil for two months led to an improved performance on the Korean MMSE and an assessment battery of frontal executive functioning in men suffering from $\mathrm{ED}[145,146]$.

Overall, with regard to cognition, PDE5-Is have yielded mixed results. Animal data, including pharmacological models mimicking characteristic features of schizophrenia, seem promising and encouraged the initiation of clinical trials. Due to the age-related decline in PDE5 levels, treatment with PDE5-Is would not be indicated in elderly, but in subjects with ED with a mean age of 55 years, cognitive improvement was reported [145]. In patients with schizophrenia, two studies were performed $[89,91]$. Positive effects were reported only after chronic treatment [91]. In this study, tests assessing cognitive performance were not included. However, the reported improvement of negative symptoms suggests that chronic PDE5 inhibition may induce cognitive improvement in schizophrenia.

\section{PDE7}

Relatively low expression of the cAMP-specific PDE type 7 family [109] might possibly explain the limited interest for the development of specific inhibitors for this family. However, the low availability of the target enzyme is not necessarily a disadvantage. The pharmacological target of PDE-Is is an intracellularly acting enzyme, which differ with regard to pharmacodynamic profile from receptors. In case of enzymes, limited inhibition might therefore prove to be optimal.

Two preclinical studies have been published that describe the effects of a PDE7-I on cognition. Lipina et al. (2013; [147]) performed a study in C57BL/6J mice treated with VP1.15 $(3 \mathrm{mg} / \mathrm{kg}$ and $7.5 \mathrm{mg} / \mathrm{kg}$ ), a dual inhibitor of PDE7 and glycogen synthase kinase-3 (GSK-3). GSK-3 is known to interact with DISC1.

An extensive cognitive battery was evaluated assessing the effects of PDE7-Is on the following domains: locomotor activity (open field), information processing (PrePulse Inhibition (PPI) of Acoustic Startle Response), attention (Latent Inhibition (LI), and memory (Puzzle-box, spatial object recognition, Y-maze, fear conditioning). VP1.15 facilitated PPI, enhanced LI, facilitated working/episodic memory and long-term cued fear memory. In addition, two pharmacological models affiliated to schizophrenia were evaluated to study the effect of VP1.15 on specific cognitive deficits. Mice received i.p. treatment with d-amphetamine to increase DA levels, and the NMDA antagonist MK-801. The authors report results obtained from the pharmacologically impaired animals on early information processing only. Amphetamine induced PPI and LI deficits could be reversed with VP1.15. MK-801 impaired PPI and LI as well, but VP1.15 treatment was unable to correct this in the MK-801 model.

In a mouse model of $\mathrm{AD}$, double transgenic $\mathrm{APP} / \mathrm{Ps} 1$ mice (5month-old) received S14 injection (i.p., $5 \mathrm{mg} / \mathrm{kg}$ daily for 4 weeks) [148]. S14 attenuated nonspatial visual recognition memory to the extent that it equalled values of wildtype control mice.

The absence of clinical trials with PDE7-Is makes it hard to predict effects in schizophrenia. Both VP1.15 and S14 inhibit PDE7, but their potential effects on DISC1 via GSK-3 could contribute to the cognitive effects as well. The development of PDE7-Is without GSK-3 inhibition will shed light on the mechanism of the reported pro-cognitive effects. Regardless of the dual inhibitory 
activity, these inhibitors might prove beneficial in the treatment of cognitive symptoms in schizophrenia.

\section{PDE8}

The cAMP-specific PDE type 8 is expressed throughout the brain, with particularly strong PDE8B expression in all cortex regions, hippocampus, thalamus and hypothalamus [109]. The distribution of PDE8 makes it an attractive target for cognitive improvement. However, to our knowledge, PDE8-Is have not been tested on cognition.

\section{PDE9}

The development of PDE9-Is is still in an early phase, but one PDE9AI has entered clinical trials that focus specifically on cognitive effects in mild to moderate AD. The first report on cognitive effects of PDE9-Is appeared in 2008. Van der Staay et al. (2008; [149]) showed enhanced acquisition, consolidation, and retention of long-term memory in a social recognition task and a tendency to enhance long-term memory in an object recognition task in rodents following BAY 73-6691 injection. Moreover, using the MK-801 model, BAY 73-6691 could partially restore disrupted functioning of the working memory as assessed with T-maze continuous alternation [149].

A second PDE9A-I named PF-04447943 is a potent inhibitor of human recombinant PDE9A, with IC50 values reaching $12 \mathrm{nM}$ and relatively good brain penetration with mouse B:P ratio 0.39 [150]. In rodents, this compound was able to significantly improve cognitive performance at 1-3 mg/kg p.o. in different assays. In mice, natural forgetting was improved in both Y maze spatial recognition and a social recognition model. In rats pre-treated with scopolamine, PF-04447943 attenuated novel object recognition [151] and attention [152]. In addition, PF-04447943 fully restored Damphetamine-induced deficits in sensory gating [150], an early information filtering process, known to be disturbed in schizophrenia [153]. The PDE9A-I PF-4449613, was able to restore this deficit as well, but less efficiently. See table 2 for an overview.

In human subjects, PF-04447943 was tested in a Phase II study in patients with mild to moderate AD [154]. Ninety-one subjects received $25 \mathrm{mg}$ (BID) for twelve weeks and were compared to a control group $(\mathrm{n}=100)$. Cognitive performance was assessed at a three week interval with Alzheimer's Disease Assessment Scalecognitive subscale, The Neuropsychiatric Inventory and Clinical Global Impression-Improvement scale. However, no effects were found on cognition in humans.

In sum, positive effects in rodents have been shown after PDE9-I treatment on different cognitive parameters relevant for schizophrenia. One clinical trial was performed in AD patients [154], but only limited data is available from this trial and results were described of one dose only. With the narrow effective range of PDE-Is, it is advisable to study at least three different dosages in a broader range. Moreover, in this study, cognitive functioning was assessed with commonly used and validated scales, but the results have limited relevance for cognitive functioning in patients with schizophrenia. Considering the effects of PDE9 on cGMP and their comparable expression (Table 1), inhibitors of this type of PDE might induce effects similar as PDE5-Is. However, at this point, it is too early to draw any conclusions on the effects of PDE9-Is in schizophrenia. Additional pre-clinical and broad range clinical studies are necessary to assess the potential of this PDE-I.

\section{PDE10}

PDE10 is a member of the dual substrate PDE family and thus affecting the breakdown of both cAMP and cGMP [11]. PDE10 mRNA is most pronouncedly expressed in the caudate nucleus and nucleus accumbens, similar to PDE1, and to a lesser extend in the $\mathrm{CA}$ regions of the hippocampus and the cortex in both rodents and humans $[109,155-157]$.
One of the most widely used PDE10-Is is papaverine. Due to the increased attention for PDE10-Is as treatment for schizophrenia, more selective PDE10-Is have been developed, including TP-10, PQ-10, MP-10, OMS824, THPP-1 and hydrazone-based small molecules, that are specific for the PDE10A isoform. These PDE-Is were developed with a focus on schizophrenia because of the high expression of PDE10A in the striatum, the single discovered isoform of the PDE10 family. PDE10 is thought to be predominantly expressed in the striatal indirect pathway and therefore considered as therapeutic drug target to treat the positive symptoms [88].

PDE10 inhibition improves memory function in unimpaired as well as in impaired rodents, including the reversal of MK-801induced memory deficits as assessed with the object recognition task and social odor recognition $[111,158]$. Furthermore, papaverine was able to reverse PCP-induced deficits in the attention shifting task in rats $[112,159]$ and compound 56, a hydrazone-based small molecule, was able to reduce PCP-induced hyperactivity [160], which should be predictive of antipsychotic property [161]. Additionally, PDE10-Is showed positive effects on information processing in general [113], but also more specifically on auditory gating and pre-pulse inhibition in rats, by reversing D-amphetamine [162] and MK-801-induced deficits [158] respectively. Finally, PDE10 inhibition disrupted conditioned avoidance responding, which is a preclinical model predictive of antipsychotic activity, showed less susceptibility to extrapyramidal side effects and improved social approach/avoidance performance in rodents [158, $162,163]$.

The above studies all describe the acute effects of PDE10-Is. One study describing long-term treatment in 8 weeks old wildtype mice reported mild cognitive disturbances and increased anxiety after 42 days of papaverine treatment [164]. The behavioural effects were accompanied by a decrease in CREB levels within the hippocampus. Treatment with the PDE10-I THPP-1 improved novel object recognition in rats and object retrieval in ketamine treated rhesus macaques. Rats receiving THPP-1 showed increased phosphorylation in the striatum of all target proteins, the GluR1 subunit of the AMPA receptor, ERK and CREB. THPP-1 seems to induce changes in biological activity of components of dopaminergic and glutamatergic pathways within the striatum [165]. The GLuR1 subunit is regulated by D1 activation, and both ERK and CREB are involved in transcription in dopaminergic and glutamatergic cells. Moreover, In MK-801 treated rats, THPP-1 attenuated psychomotor activation, which has claimed to be predictive of antipsychotic property [165].

In patients with schizophrenia, the PDE10A-I PF-2545920 (or MP-10) was tested in a second Phase-II clinical study after a first study had been terminated, the reasons of which were not disclosed. PF-2545920 5mg, $15 \mathrm{mg}$ and placebo were administered (BID) to three groups of 74 patients, and 36 additional subjects received the atypical antipsychotic risperidone. Patients were diagnosed with schizophrenia and presented with an acute exacerbation of their symptoms [166]. After 4 weeks of treatment, the PF-2545920 treatment group showed no improvement as compared to the placebo group, whereas the risperidone group did show a decrease in total Positive and Negative Symptom Scale (PANNS) score. Whether there were any effects on cognition in these patients is not known to us. Moreover, cognitive effects should not be assessed in the acute state [167]. Thus, the usefulness of PDE10 inhibition to treat schizophrenia appears limited based on this first study. However, pre-clinical data including cognitive parameters are encouraging. Therefore, a study on cognitive outcomes in patients not in acute state is warranted.

\section{PDE11}

PDE11 is the most recently discovered family of PDEs and is a dual substrate PDE [11]. This family contains one gene, PDE11A, 
with four isoforms (PDE11A1-PDE11A4). The physiological role of PDE11A is not clear yet.

\section{DISCUSSION AND CONCLUSION}

PDE-Is prolong the availability of the second messengers cAMP and/or cGMP. These second messengers play an important role within the neurotransmitter systems that are affected in schizophrenia. Since neurotransmitter systems are subject to strong interactions, malfunctioning of one system can induce or aggravate problems of a second system. In theory, optimizing the signalling of the hypofunctional postsynaptic NMDA receptors on GABAergic interneurons in the frontal cortex should improve both positive symptoms and negative/cognitive symptoms. The hypofunctional post-synaptic NMDA receptors in these neurons prevent sufficient inhibition of the glutamatergic cortical brainstem projection, a descending pathway projecting from the prefrontal cortex to brainstem centers, including the ventral tegmental area [57]. The second messengers cAMP and cGMP are involved in the synthesis and release of glutamate. Limiting the degradation of cAMP and cGMP by introducing PDE-Is restores the signal of the inhibitory GABAergic interneuron.

With regard to the cognitive symptoms and the underlying neurochemical disturbances that are thought to operate in schizophrenia, the reduced dopaminergic tone in the PFC should be targeted (see Fig. 2). In this area, the D1 receptor is the main post-synaptic DA receptor. As described above, D1 receptors are Gs-coupled receptors which act via cAMP signalling. Thus, in addition to opti- malisation of NMDA function in GABAergic interneurons in the cortex, PDE-Is could have a binary effect by simultaneously improving the signal of post-synaptic D1 receptors. Preferably, these effects should be limited to the frontal cortex. PDEs for which selective inhibitors are available are present in the frontal cortex in humans (see Table 1) and offer potential for treatment options. This has already been demonstrated in mouse brain with the PDE4-I rolipram [168]. Moreover, in addition to enhanced D1 signalling, the authors showed an increased pre-pulse inhibition of the acoustic startle response in mice, suggestive of its ability to improve early information processing.

Of the three PDE-Is actually tested in patients with schizophrenia, i.e. PDE3, 5, and 10, only the PDE3-I cilostazol showed indications for improvement of cognitive symptoms. This is in contrast to the encouraging results with PDE5-Is and PDE10-Is obtained in animal studies in which NMDA antagonists were applied, mimicking the dysfunctional NMDA receptors as described in schizophrenia. Thus, the question arises why this does not translate to humans, especially since the inhibition of PDE3 apparently does show indications of positive effects in humans. Characteristic for PDE3-Is is their dual inhibitory activity in combination with their ability to increase cerebral blood flow. At this point, it is unclear whether the cognitive improvement is related to PDE inhibitory activity affecting both cAMP and cGMP levels, to increased cerebral blood flow, or to a combined effect. Moreover, PDE3 mRNA as well as PDE5 and PDE10 mRNA show low relative expression rates within the human brain, including the PFC, with the exception of the high

Table 2. Cognitive outcomes of PDE-I treatment in preclinical models related to schizophrenia.

\begin{tabular}{|c|c|c|c|c|}
\hline PDE family & Model & Animal & Test & Outcome \\
\hline \multirow[t]{3}{*}{2} & \multirow[t]{2}{*}{ MK-801 } & rat & T-maze continuous alternation [110] & + \\
\hline & & rat & Object recognition task [111] & + \\
\hline & PCP & rat & Extradimensional-intradimensional test [112] & + \\
\hline 4 & PCP & rat & Extradimensional-intradimensional test [112] & + \\
\hline \multirow[t]{2}{*}{5} & MK-801 & rat & Object recognition task [140] & $+(*)$ \\
\hline & PCP & rat & Extradimensional-intradimensional test [112] & + \\
\hline \multirow[t]{3}{*}{$7(* *)$} & MK-801 & mouse & Prepulse inhibition [147] & $=$ \\
\hline & \multirow[t]{2}{*}{ D-amphetamine } & \multirow[t]{2}{*}{ mouse } & Prepulse inhibition [147] & + \\
\hline & & & Latent inhibition [147] & + \\
\hline \multirow[t]{4}{*}{9} & \multirow[t]{2}{*}{ MK-801 } & mouse & T-maze continuous alternation [149] & + \\
\hline & & mouse & Prepulse inhibition of acoustic startle response [150] & $=$ \\
\hline & D-amphetamine & rat & Auditory gating [150] & + \\
\hline & Ketamine & rat & Radial arm maze $[150]$ & + \\
\hline \multirow[t]{8}{*}{10} & \multirow[t]{4}{*}{ MK-801 } & rat & Object recognition task [111] & + \\
\hline & & rat & Prepulse inhibition of acoustic startle response [158] & + \\
\hline & & & Social odor recognition $[158]$ & \\
\hline & & mouse & & + \\
\hline & PCP & rat & Extradimensional-intradimensional test $[112 ; 159]$ & + \\
\hline & & & Auditory gating [162] & \\
\hline & D-amphetamine & rat & Object retrieval [165] & + \\
\hline & Ketamine & rhesus & & + \\
\hline
\end{tabular}

+: normalizes disrupted function at optimal dose; *Memory disruption was not restored with the PDE5-I UK-343,664, a PDE5-I that does not penetrate the BBB; **VP1.15 was used in this study which is not selective for PDE7, but also inhibits glycogen synthase kinase-3. 
expression of PDE10 in the caudate nucleus [109]. Similar to PDE3, PDE10 is a dual inhibitor, but its action is assumed to be predominantly directed at cAMP. PDE5 has only cGMP as substrate. As mentioned above, it is likely that an increase in cognitive functioning is related to upregulation of NMDA receptor - D1 receptor signalling pathways. The former can be stimulated by increasing cAMP and/or cGMP, while the latter can be stimulated by increasing cAMP only. In the end, the exact location of specific PDEs in these signalling pathways determines their role. Whether this contributes to the discrepancy between human and animal studies remains to be investigated. Another point of discussion is the kind of animal models that have been used to test the potential of PDE-Is. Until now, cognitive function has been assessed only in animal models dependent on pharmacologically induced symptoms that are mechanistically and behaviourally related to schizophrenia (Table 2). Genetic models, lesion models and models of developmental disorders of primary brain structures have the advantage of sustained distortion of normal function, including developmental aspects and the absence of drug interactions [169]. Preferably, cognitive testing should not be limited to pharmacological models.

Direct comparison of the methodological aspects of the human studies reveals some major differences which might explain the different outcomes. The PDE3-I cilostazol was administered for eight weeks [91], whereas the PDE5-I sildenafil was administered acutely in a trial in which cognition was assessed [89]. Long-term treatment with sildenafil did improve negative symptoms [91]. Since negative and cognitive symptoms in schizophrenia largely rely on the same signalling pathways [57], it is conceivable that patients with a diagnosis of schizophrenia will benefit from chronic sildenafil treatment with regard to their cognitive impairments. However, these patients were tested in the active phase of the illness, with the threshold for the negative subscale of the PANNS set at a minimum score of 20. Cognitive effects should preferably be assessed in a stable phase [167]. It is difficult to predict whether sildenafil will have an equally strong effect on negative and possibly cognitive symptoms in the absence of acute pathology.

More generally, it has been acknowledged that many factors among which clinical status, disease severity and duration, and pharmacological profile, contribute to the heterogeneity of patient populations, which hampers comparability. Guidelines developed specifically to assess more uniformly the effects of cognition en- hancers in patients with schizophrenia [167] were followed only partly by the studies described above, or were not described explicitely. For instance, indications on disease severity, and illicit drug and medication use were not always provided, or patients were unstable, or stable for a relatively brief period of time.

At this point, it is too early to draw conclusions from the studies performed in human subjects (Table 3 ). The finding of improved negative symptoms with sildenafil and improved cognitive functions after cilostazol are encouraging. However, since the cilostazol study was performed according to an open-label design and included only six subjects [90], replication in a larger, well-controlled sample is warranted.

Most research on cognitive impairment in schizophrenia has focused on prefrontal functions. However, dysfunction of the medial temporal lobe, affecting in particular episodic memory, is also observed in patients with a diagnosis of schizophrenia. An early meta-analysis showed considerable memory deficits in patients with schizophrenia, in particular impaired recall. The authors suggested that a combination of impaired consolidation and possibly impaired retrieval was the underlying problem [170]. Others have disputed this and claim that it can be attributed primarily to comorbid depressive states [171]. Irrespective of the underlying mechanism, stimulating synaptic plasticity within the medial temporal lobe should alleviate memory problems related to consolidation and retrieval. Therefore, results from studies in which PDE-Is were applied to ameliorate mental states characterized by impaired memory functioning, could predict the potential of PDE-Is with regard to retrieval in schizophrenia.

Memory function of both patients with $\mathrm{AD}$ and milder forms of memory impairment, as well as of healthy subjects has been assessed following PDE-I treatment. In AD, treatment with the PDE1I vinpocetine and PDE9-I PF-04447943 did not improve memory. Remarkably, long-term treatment with the PDE3-I cilostazol 100 $\mathrm{mg}$ /day prevented further deterioration [117] and even improved memory [121] in mild to moderate AD patients. In a third study (Lee (personal communication); ClinicalTrials.gov identifier: NCT01409564), a dose of cilostazol twice as high was administered to $\mathrm{AD}$ patients, but was found to be ineffective in improving cognitive function. The effective dose range of PDE-Is is known to be fairly small, according to an inverted U-shape profile found in numerous preclinical studies (e.g. [92]). This could possibly explain

Table 3. General overview of outcomes of studies relating PDE-Is and cognitive functioning related to schizophrenia.

\begin{tabular}{|c|c|c|c|c|c|}
\hline & Schizophrenia & Alzheimer's Disease & Aged/Mild impairment & Unimpaired subjects & Animal models of schizophrenia \\
\hline PDE3 & + & $+/=$ & NT & NT & NT \\
\hline PDE4 & NT & NT & + & NT & + \\
\hline \multicolumn{6}{|l|}{ PDE6 } \\
\hline PDE7 & NT & NT & NT & NT & $+/=$ \\
\hline PDE8 & NT & NT & NT & NT & NT \\
\hline PDE9 & NT & $=$ & NT & NT & $+/=$ \\
\hline
\end{tabular}

$=:$ no effect; +: improvement; NT: not tested 
the discrepancy between results. Moreover, in the study of Shirayama et al. (2011) in patients with schizophrenia, cognitive improved was achieved at doses as low as $50 \mathrm{mg}$ daily.

The PDE1-I vinpocetine showed positive effects in Mild Cognitive Impairment [101], organic psychosyndromes [102], elderly with chronic cerebral dysfunction [103] as well as in healthy female volunteers [104]. In $\mathrm{AD}$, mixed results have been described [100, 106]. Crucial for the function of PDE-Is are intact neuronal pathways. PDE-Is can exert their stimulatory effects only on intracellular cascades after binding of a first messenger to its receptor. Therefore, the effect of PDE-Is in AD might be dependent on the degree of neurodegeneration. In early or prodromal states, the effect of PDE-Is might be stronger due to higher availability of its target enzyme.

Positive findings in age-associated memory impairment have also been described for the PDE4-I HT-0712. Unfortunately, study details were not disclosed. However, in unimpaired subjects, single dose administration of the PDE5-I sildenafil did not show effects on a behavioural level, although electrophysiological changes were observed [142, 143]. This could be in line with the absence of memory improvement in patients with schizophrenia.

Inhibition of both cAMP and cGMP specific PDEs show positive results in animal models of schizophrenia as well as in human memory impairment. Combining these effects with a dual inhibitor might therefore be favourable. So far, positive effects on cognitive symptoms in schizophrenia have only been obtained in a study with the clear dual-substrate inhibitor cilostazol. Therefore, there is a need of a larger trial with a specific PDE3I. Other dual-substrate inhibitors including PDE1 and 2 that not have been tested in patients with schizophrenia yet, but might prove to be effective as well, especially considering their positive effect in animal studies on memory (PDE1-I; [172]; PDE2; [110]). PDE1 might be of special interest due to its specific calcium/calmodulin-dependent activity with no effect on basal cyclic nucleotide signalling. Increased levels of intracellular calcium trigger its enzymatic action. Since cognitive processes rely on neurotransmitter signalling, effects of PDE1 inhibition are therefore only effective during such processes, not affecting basal states.

PDE10-Is have received most attention as potential drug to treat positive symptoms in schizophrenia due to the high expression of the target enzyme in the striatum [109]. Animal studies have indeed shown positive results, but the only study in human subjects with schizophrenia did not show improvement as assessed with the PANNS [166]. However, in this study subjects with acute exacerbation of their complaints were included. Therefore, the results of this study are most indicative of a possible effect of a PDE10-I on positive symptoms. As stated before, cognitive traits in schizophrenia are stable and persist in between episodes characterized by psychotic symptoms. Since impaired cognitive functioning is a strong contributor to the decreased quality of life, efforts should be made to improve overall cognitive functioning, in particular during periods in which patients are relatively stable. A clinical trial with a PDE10-I in which a cognitive test battery is included, will be needed before definite conclusions can be drawn on the potential of PDE10 inhibition to treat schizophrenia.

In conclusion, considering the critical role of the second messengers cAMP and cGMP in the effectuation of neurotransmitter signalling, preventing their breakdown directly potentiates the effects of different neurotransmitter systems throughout the brain. In schizophrenia, strengthening the signal of both the dysfunctional NMDA receptors and the post-synaptic D1 receptors in the PFC should improve cognitive functioning in these patients. Results from animal studies are hopeful, but still need to show their translational value. Taking into account the limited data available from clinical trials, PDE3-Is seem most promising, with positive effects reported on cognitive symptoms in schizophrenia and memory im- provement in $\mathrm{AD}$. Other dual inhibitors have shown positive effects on cognition in unimpaired subjects (PDE1-I) and animal models of schizophrenia (PDE2-I, PDE10-I) and long-term clinical trials in patients with schizophrenia in a stable phase are warranted. Especially PDE1-Is are of interest due to the calcium/calmodulindependent activity of PDE1s. cGMP specific PDE-Is seem promising as well considering their effects in animals models and the positive effects of the PDE5-I sildenafil on negative symptoms.

The field is still in its infancy, but the first results are encouraging. Cognitive improvement in patients with schizophrenia currently is an unmet need and the potential gain is significant. Current developments in the field of PDE-Is may be hopeful in this respect, and therefore further research on the cognition enhancing effects of PDE-Is in this disorder should be stimulated.

\section{ABBREVIATIONS}

\begin{tabular}{|c|c|c|}
\hline $\operatorname{PDE}(-\mathrm{I})$ & $=$ & phosphodiesterase (inhibitor) \\
\hline DLPFC & $=$ & dorsolateral prefrontal cortex \\
\hline $\mathrm{ACC}$ & $=$ & anterior cingulate cortex \\
\hline $\mathrm{IP}_{3} / \mathrm{DAG}$ & $=$ & inositol-1, 4, 5, triphosphate/diacylglycerol \\
\hline $\mathrm{PIP}_{2}$ & $=$ & phosphatidylinositol 4, 5-biphosphate \\
\hline PLC & $=$ & phospholipase C \\
\hline $\mathrm{AC}$ & $=$ & adenylate cyclase \\
\hline NMDA & $=$ & $N$-Methyl-D-aspartate \\
\hline CaMK & $=$ & $\mathrm{Ca}^{2+} / \mathrm{CaM}$ protein kinase \\
\hline AMPA & $=$ & $\begin{array}{l}\alpha \text {-Amino-3-hydroxy-5-methylisoxazole-4- } \\
\text { propionic acid }\end{array}$ \\
\hline $\mathrm{PKC}$ & $=$ & phosphokinase C \\
\hline cAMP & $=$ & cyclic adenosine monophosphate \\
\hline CREB & $=$ & cAMP response element binding protein \\
\hline NOS & $=$ & nitric oxide synthase \\
\hline $\mathrm{GC}$ & $=$ & guanylate cyclase \\
\hline PKG & $=$ & cGMP-dependent protein kinase \\
\hline GABA & $=$ & $\gamma$-Aminobutyric acid \\
\hline DA & $=$ & dopamine \\
\hline $\mathrm{D} 1 / 2$ receptor & $=$ & DA receptor type $1 / 2$ \\
\hline $5-\mathrm{HT}$ & $=$ & serotonin \\
\hline $\mathrm{ACh}$ & $=$ & acetylcholine \\
\hline PCP & $=$ & phenylcyclohexylpiperidine \\
\hline $\mathrm{AD}$ & $=$ & Alzheimer's Disease \\
\hline MMSE & $=$ & Mini-Mental State Exam \\
\hline DISC1 & $=$ & Disrupted-in Schizophrenia-1 \\
\hline PPI & $=$ & PrePulse Inhibition \\
\hline LI & $=$ & latent inhibition \\
\hline GSK-3 & $=$ & glycogen synthase kinase-3 \\
\hline PANNS & $=$ & Positive and Negative Symptom Scale \\
\hline
\end{tabular}

\section{CONFLICT OF INTEREST}

The authors confirm that this article content has no conflicts of interest.

\section{ACKNOWLEDGEMENTS}

Declared none.

\section{REFERENCES}

[1] Green MF. What are the functional consequences of neurocognitive deficits in schizophrenia? Am J Psychiatry 1996; 153: 321-30. 
[2] Green MF, Kern RS, Braff DL, Mintz J. Neurocognitive deficits and functional outcome in schizophrenia: are we measuring the "right stuff"? Schizophr Bull 2000; 26: 119-36.

[3] McGurk SR. Neurocognition as a determinant of employment status in schizophrenia. J Psychiatr Pract 2000; 6: 190-6.

[4] Kitchen H, Rofail D, Heron L, Sacco P. Cognitive impairment associated with schizophrenia: a review of the humanistic burden. Adv Ther 2012; 29: 148-62.

[5] Barch DM, Ceaser A. Cognition in schizophrenia: core psychological and neural mechanisms. Trends Cogn Sci 2012; 16: 27-34.

[6] Davidson M, Reichenberg A, Rabinowitz J, et al. Behavioral and intellectual markers for schizophrenia in apparently healthy male adolescents. Am J Psychiatry 1999; 156: 1328-35.

[7] Cannon TD, Bearden CE, Hollister JM, et al. Childhood cognitive functioning in schizophrenia patients and their unaffected siblings: a prospective cohort study. Schizophr Bull 2000; 26: 379-93.

[8] Rajji TK, Ismail Z, Mulsant BH. Age at onset and cognition in schizophrenia: meta-analysis. Br J Psychiatry 2009; 195: 286-93.

[9] Lewandowski KE, Cohen BM, Ongur D. Evolution of neuropsychological dysfunction during the course of schizophrenia and bipolar disorder. Psychol Med 2011; 41: 225-41.

[10] Dickson H, Laurens KR, Cullen AE, Hodgins S. Meta-analyses of cognitive and motor function in youth aged 16 years and younger who subsequently develop schizophrenia. Psychol Med 2012; 42 : 743-55.

[11] Bender AT, Beavo JA. Cyclic nucleotide phosphodiesterases: molecular regulation to clinical use. Pharmacol Rev 2006; 58: 488520 .

[12] Stip E, Chouinard S, Boulay LJ. On the trail of a cognitive enhancer for the treatment of schizophrenia. Prog Neuropsychopharmacol Biol Psychiatry 2005; 29: 219-32.

[13] Keefe RS, Harvey PD. Cognitive impairment in schizophrenia. Handb Exp Pharmacol 2012: 11-37.

[14] Rushworth MF, Mars RB, Sallet J. Are there specialized circuits for social cognition and are they unique to humans? Curr Opin Neurobiol 2013; 23: 436-42.

[15] Elliott R. Executive functions and their disorders. Br Med Bull 2003; 65: 49-59.

[16] Lesh TA, Niendam TA, Minzenberg MJ, Carter CS. Cognitive control deficits in schizophrenia: mechanisms and meaning. Neuropsychopharmacology 2011; 36: 316-38.

[17] Minzenberg MJ, Laird AR, Thelen S, Carter CS, Glahn DC. Metaanalysis of 41 functional neuroimaging studies of executive function in schizophrenia. Arch Gen Psychiatry 2009; 66: 811-22.

[18] Cohen JD, Barch DM, Carter C, Servan-Schreiber D. Contextprocessing deficits in schizophrenia: converging evidence from three theoretically motivated cognitive tasks. J Abnorm Psychol 1999; 108: 120-33.

[19] Ragland JD, Laird AR, Ranganath C, et al. Prefrontal activation deficits during episodic memory in schizophrenia. Am J Psychiatry 2009; 166: 863-74.

[20] Heckers S, Konradi C. Hippocampal pathology in schizophrenia. Curr Top Behav Neurosci 2010; 4: 529-53.

[21] Prestia A, Boccardi M, Galluzzi S, et al. Hippocampal and amygdalar volume changes in elderly patients with Alzheimer's disease and schizophrenia. Psychiatry Res 2011; 192: 77-83.

[22] Fusar-Poli P, Smieskova R, Kempton MJ, et al. Progressive brain changes in schizophrenia related to antipsychotic treatment? A meta-analysis of longitudinal MRI studies. Neurosci Biobehav Rev 2013; 37: 1680-91.

[23] Habets P, Krabbendam L, Hofman P, et al. Cognitive performance and grey matter density in psychosis: functional relevance of a structural endophenotype. Neuropsychobiology 2008; 58: 128-37.

[24] Modinos G, Costafreda SG, van Tol MJ, et al. Neuroanatomy of auditory verbal hallucinations in schizophrenia: a quantitative meta-analysis of voxel-based morphometry studies. Cortex 2013; 49: 1046-55.

[25] Ortiz-Gil J, Pomarol-Clotet E, Salvador R, et al. Neural correlates of cognitive impairment in schizophrenia. Br J Psychiatry 2011; 199: 202-10.

[26] Yao L, Lui S, Liao Y, et al. White matter deficits in first episode schizophrenia: an activation likelihood estimation meta-analysis. Prog Neuropsychopharmacol Biol Psychiatry 2013; 45: 100-6.

[27] Haijma SV, Van Haren N, Cahn W, et al. Brain volumes in schizophrenia: a meta-analysis in over 18000 subjects. Schizophr Bull 2013; 39: 1129-38.
[28] Vita A, De Peri L, Deste G, Sacchetti E. Progressive loss of cortical gray matter in schizophrenia: a meta-analysis and meta-regression of longitudinal MRI studies. Trans Psychiatry 2012; 2: e190.

[29] Olabi B, Ellison-Wright I, Bullmore E, Lawrie SM. Structural brain changes in First Episode Schizophrenia compared with FrontoTemporal Lobar Degeneration: a meta-analysis. BMC Psychiatry 2012; 12: 104 .

[30] Shepherd AM, Matheson SL, Laurens KR, Carr VJ, Green MJ. Systematic meta-analysis of insula volume in schizophrenia. Biol Psychiatry 2012; 72: 775-84.

[31] Palaniyappan L, Balain V, Liddle PF. The neuroanatomy of psychotic diathesis: a meta-analytic review. J Psychiatr Res 2012; 46: 1249-56.

[32] Palaniyappan L, Balain V, Radua J, Liddle PF. Structural correlates of auditory hallucinations in schizophrenia: a meta-analysis. Schizophr Res 2012; 137: 169-73.

[33] Shah BH, Catt KJ. GPCR-mediated transactivation of RTKs in the CNS: mechanisms and consequences. Trends Neurosci 2004; 27: 48-53.

[34] Wei JY, Roy DS, Leconte L, Barnstable CJ. Molecular and pharmacological analysis of cyclic nucleotide-gated channel function in the central nervous system. Prog Neurobiol 1998; 56: 37-64.

[35] Lu YF, Hawkins RD. Ryanodine receptors contribute to cGMPinduced late-phase LTP and CREB phosphorylation in the hippocampus. J Neurophysiol 2002; 88: 1270-8.

[36] Scott Bitner R. Cyclic AMP response element-binding protein (CREB) phosphorylation: a mechanistic marker in the development of memory enhancing Alzheimer's disease therapeutics. Biochem Pharmacol 2012; 83: 705-14.

[37] Sweatt JD. Toward a molecular explanation for long-term potentiation. Learn Mem 1999; 6: 399-416.

[38] Schoffelmeer AN, Wardeh G, Mulder AH. Cyclic AMP facilitates the electrically evoked release of radiolabelled noradrenaline, dopamine and 5-hydroxytryptamine from rat brain slices. Naunyn Schmiedebergs Arch Pharmacol 1985; 330: 74-6.

[39] Imanishi T, Sawa A, Ichimaru Y, et al. Ameliorating effects of rolipram on experimentally induced impairments of learning and memory in rodents. Eur J Pharmacol 1997; 321: 273-8.

[40] Rodriguez-Moreno A, Sihra TS. Presynaptic kainate receptormediated facilitation of glutamate release involves $\mathrm{Ca} 2+$ calmodulin and PKA in cerebrocortical synaptosomes. FEBS Lett 2013; 587: 788-92.

[41] Murad F, Mittal CK, Arnold WP, Katsuki S, Kimura H. Guanylate cyclase: activation by azide, nitro compounds, nitric oxide, and hydroxyl radical and inhibition by hemoglobin and myoglobin. Adv Cyclic Nucleotide Res 1978; 9: 145-58.

[42] Lu YF, Kandel ER, Hawkins RD. Nitric oxide signaling contributes to late-phase LTP and CREB phosphorylation in the hippocampus. J Neurosci 1999; 19: 10250-61.

[43] Arancio O, Kandel ER, Hawkins RD. Activity-dependent longterm enhancement of transmitter release by presynaptic 3', 5'-cyclic GMP in cultured hippocampal neurons. Nature 1995; 376: 74-80.

[44] Sanchez JJ, Abreu P, Gonzalez MC. Sodium nitroprusside stimulates L-DOPA release from striatal tissue through nitric oxide and cGMP. Eur J Pharmacol 2002; 438: 79-83.

[45] van Rossum JM. The significance of dopamine-receptor blockade for the mechanism of action of neuroleptic drugs. Arch Int Pharmacodyn Ther 1966; 160: 492-4.

[46] Grace AA. Gating of information flow within the limbic system and the pathophysiology of schizophrenia. Brain Res Brain Res Rev 2000; 31: 330-41.

[47] Abi-Dargham A. The Dopamine Hypothesis of Schizophrenia. http://www.schizophreniaforum.org/for/curr/AbiDargham/, 2005. Obtained: November 2013.

[48] Marsden CA. Dopamine: the rewarding years. Br J Pharmacol 2006; 147 (Suppl 1): S136-44.

[49] Howes OD, Kapur S. The dopamine hypothesis of schizophrenia: version III--the final common pathway. Schizophr Bull 2009; 35: 549-62.

[50] Perez-Costas E, Melendez-Ferro M, Roberts RC. Basal ganglia pathology in schizophrenia: dopamine connections and anomalies. J Neurochem 2010; 113: 287-302.

[51] Winterer G. Cortical microcircuits in schizophrenia--the dopamine hypothesis revisited. Pharmacopsychiatry 2006; 39 (Suppl 1): S6871 . 
[52] Winterer G, Weinberger DR. Genes, dopamine and cortical signalto-noise ratio in schizophrenia. Trends Neurosci 2004; 27: 683-90.

[53] Kim JS, Kornhuber HH, Schmid-Burgk W, Holzmuller B. Low cerebrospinal fluid glutamate in schizophrenic patients and a new hypothesis on schizophrenia. Neurosci Lett 1980; 20: 379-82.

[54] Javitt DC, Zukin SR. Recent advances in the phencyclidine model of schizophrenia. Am J Psychiatry 1991; 148: 1301-8.

[55] Krystal JH, Karper LP, Seibyl JP, et al. Subanesthetic effects of the noncompetitive NMDA antagonist, ketamine, in humans. Psychotomimetic, perceptual, cognitive, and neuroendocrine responses. Arch Gen Psychiatry 1994; 51: 199-214.

[56] Akbarian S, Sucher NJ, Bradley D, et al. Selective alterations in gene expression for NMDA receptor subunits in prefrontal cortex of schizophrenics. J Neurosci 1996; 16: 19-30.

[57] Schwartz TL, Sachdeva S, Stahl SM. Glutamate neurocircuitry: theoretical underpinnings in schizophrenia. Front Pharmacol 2012; 3: 195.

[58] Lewis DA, Hashimoto T, Volk DW. Cortical inhibitory neurons and schizophrenia. Nat Rev Neurosci 2005; 6: 312-24.

[59] Akbarian S, Kim JJ, Potkin SG, et al. Gene expression for glutamic acid decarboxylase is reduced without loss of neurons in prefrontal cortex of schizophrenics. Arch Gen Psychiatry 1995; 52: 258-66.

[60] Volk DW, Austin MC, Pierri JN, Sampson AR, Lewis DA. Decreased glutamic acid decarboxylase67 messenger RNA expression in a subset of prefrontal cortical gamma-aminobutyric acid neurons in subjects with schizophrenia. Arch Gen Psychiatry 2000; 57: 23745 .

[61] Knable MB, Barci BM, Bartko JJ, Webster MJ, Torrey EF. Molecular abnormalities in the major psychiatric illnesses: Classification and Regression Tree (CRT) analysis of post-mortem prefrontal markers. Mol Psychiatry 2002; 7: 392-404.

[62] Volk D, Austin M, Pierri J, Sampson A, Lewis D. GABA transporter-1 mRNA in the prefrontal cortex in schizophrenia: decreased expression in a subset of neurons. Am J Psychiatry 2001; 158: 25665 .

[63] Gurevich EV, Joyce JN. Alterations in the cortical serotonergic system in schizophrenia: a postmortem study. Biol Psychiatry 1997; 42: 529-45.

[64] Bortolato M, Pivac N, Muck Seler D, et al. The role of the serotonergic system at the interface of aggression and suicide. Neuroscience 2013; 236: 160-85.

[65] Meltzer HY, McGurk SR. The effects of clozapine, risperidone, and olanzapine on cognitive function in schizophrenia. Schizophr Bull 1999; 25: 233-55.

[66] Woodward ND, Purdon SE, Meltzer HY, Zald DH. A metaanalysis of neuropsychological change to clozapine, olanzapine, quetiapine, and risperidone in schizophrenia. Int J Neuropsychopharmacol 2005; 8: 457-72.

[67] Marek GJ, Wright RA, Schoepp DD, Monn JA, Aghajanian GK. Physiological antagonism between 5-hydroxytryptamine(2A) and group II metabotropic glutamate receptors in prefrontal cortex. J Pharmacol Exp Ther 2000; 292: 76-87.

[68] Sumiyoshi T, Bubenikova-Valesova V, Horacek J, Bert B. Serotonin1 A receptors in the pathophysiology of schizophrenia: development of novel cognition-enhancing therapeutics. Adv Ther 2008; 25: $1037-56$

[69] Ichikawa J, Ishii $\mathrm{H}$, Bonaccorso $\mathrm{S}$, et al. 5-HT(2A) and $\mathrm{D}(2)$ receptor blockade increases cortical DA release via 5-HT(1A) receptor activation: a possible mechanism of atypical antipsychotic-induced cortical dopamine release. J Neurochem 2001; 76: 1521-31.

[70] Ribeiz SR, Bassitt DP, Arrais JA, et al. Cholinesterase inhibitors as adjunctive therapy in patients with schizophrenia and schizoaffective disorder: a review and meta-analysis of the literature. CNS Drugs 2010; 24: 303-17.

[71] Zugno AI, Juliao RF, Budni J, et al. Rivastigmine reverses cognitive deficit and acetylcholinesterase activity induced by ketamine in an animal model of schizophrenia. Metab Brain Dis 2013; 28(3): 501-8.

[72] Crook JM, Tomaskovic-Crook E, Copolov DL, Dean B. Low muscarinic receptor binding in prefrontal cortex from subjects with schizophrenia: a study of Brodmann's areas 8, 9, 10, and 46 and the effects of neuroleptic drug treatment. Am J Psychiatry 2001; 158: 918-25.

[73] Liskowsky DR, Potter LT. Muscarine-binding sites localized to cortical dopamine terminals. Neurosci Lett 1985; 58: 229-33.
[74] Chesselet MF. Presynaptic regulation of neurotransmitter release in the brain: facts and hypothesis. Neuroscience 1984; 12: 347-75.

[75] Clarke PB, Pert A. Autoradiographic evidence for nicotine receptors on nigrostriatal and mesolimbic dopaminergic neurons. Brain Res 1985; 348: 355-8.

[76] Colquhoun LM, Patrick JW. Pharmacology of neuronal nicotinic acetylcholine receptor subtypes. Adv Pharmacol 1997; 39: 191220.

[77] Sorenson EM, Shiroyama T, Kitai ST. Postsynaptic nicotinic receptors on dopaminergic neurons in the substantia nigra pars compacta of the rat. Neuroscience 1998; 87: 659-73.

[78] Gronier B, Rasmussen K. Activation of midbrain presumed dopaminergic neurones by muscarinic cholinergic receptors: an in vivo electrophysiological study in the rat. Br J Pharmacol 1998; 124: 455-64.

[79] De Klippel N, Sarre S, Ebinger G, Michotte Y. Effect of M1- and M2-muscarinic drugs on striatal dopamine release and metabolism: an in vivo microdialysis study comparing normal and 6hydroxydopamine-lesioned rats. Brain Res 1993; 630: 57-64.

[80] Livingstone PD, Srinivasan J, Kew JN, et al. alpha7 and nonalpha7 nicotinic acetylcholine receptors modulate dopamine release in vitro and in vivo in the rat prefrontal cortex. Eur $\mathrm{J}$ Neurosci 2009; 29: 539-50.

[81] Parikh V, Ji J, Decker MW, Sarter M. Prefrontal beta2 subunitcontaining and alpha7 nicotinic acetylcholine receptors differentially control glutamatergic and cholinergic signaling. J Neurosci 2010; 30: 3518-30.

[82] dos Santos Coura R, Granon S. Prefrontal neuromodulation by nicotinic receptors for cognitive processes. Psychopharmacology (Berl) 2012; 221: 1-18.

[83] Olincy A, Harris JG, Johnson LL, et al. Proof-of-concept trial of an alpha7 nicotinic agonist in schizophrenia. Arch Gen Psychiatry 2006; 63: 630-8.

[84] Nishi A, Kuroiwa M, Shuto T. Mechanisms for the modulation of dopamine d(1) receptor signaling in striatal neurons. Front Neuroanat 2011; 5: 43.

[85] Myhrer T. Neurotransmitter systems involved in learning and memory in the rat: a meta-analysis based on studies of four behavioral tasks. Brain Res Brain Res Rev 2003; 41: 268-87.

[86] Rose GM, Hopper A, De Vivo M, Tehim A. Phosphodiesterase inhibitors for cognitive enhancement. Curr Pharm Des 2005; 11: 3329-34.

[87] Nishi A, Kuroiwa M, Miller DB, et al. Distinct roles of PDE4 and PDE10A in the regulation of cAMP/PKA signaling in the striatum. J Neurosci 2008; 28: 10460-71.

[88] Nishi A, Snyder GL. Advanced research on dopamine signaling to develop drugs for the treatment of mental disorders: biochemical and behavioral profiles of phosphodiesterase inhibition in dopaminergic neurotransmission. J Pharmacol Sci 2010; 114: 6-16.

[89] Goff DC, Cather C, Freudenreich O, et al. A placebo-controlled study of sildenafil effects on cognition in schizophrenia. Psychopharmacology (Berl) 2009; 202: 411-7.

[90] Shirayama Y, Konishi T, Hashimoto K. Effects of add-on cilostazol on cognition in patients with schizophrenia: an open-label pilot trial. J Clin Psychopharmacol 2011; 31: 659-61.

[91] Akhondzadeh S, Ghayyoumi R, Rezaei F, et al. Sildenafil adjunctive therapy to risperidone in the treatment of the negative symptoms of schizophrenia: a double-blind randomized placebocontrolled trial. Psychopharmacology (Berl) 2011; 213: 809-15.

[92] Reneerkens OA, Rutten K, Steinbusch HW, Blokland A, Prickaerts J. Selective phosphodiesterase inhibitors: a promising target for cognition enhancement. Psychopharmacology (Berl) 2009; 202: 419-43.

[93] Javitt DC, Zukin SR, Heresco-Levy U, Umbricht D. Has an angel shown the way? Etiological and therapeutic implications of the PCP/NMDA model of schizophrenia. Schizophr Bull 2012; 38: 958-66.

[94] Neill JC, Barnes S, Cook S, et al. Animal models of cognitive dysfunction and negative symptoms of schizophrenia: focus on NMDA receptor antagonism. Pharmacol Ther 2010; 128: 419-32.

[95] Frohlich J, Van Horn JD. Reviewing the ketamine model for schizophrenia. J Psychopharmacol 2014; 28(4): 287-302.

[96] Lal S, Sharma RK, McGregor C, Macaulay RJ. Immunohistochemical localization of calmodulin-dependent cyclic phosphodiesterase in the human brain. Neurochem Res 1999; 24: 43-9. 
[97] Lugnier C. Cyclic nucleotide phosphodiesterase (PDE) superfamily: a new target for the development of specific therapeutic agents. Pharmacol Ther 2006; 109: 366-98.

[98] Deshmukh R, Sharma V, Mehan S, Sharma N, Bedi KL. Amelioration of intracerebroventricular streptozotocin induced cognitive dysfunction and oxidative stress by vinpocetine -- a PDE1 inhibitor. Eur J Pharmacol 2009; 620: 49-56.

[99] Greengard P. Deal watch: Intra-Cellular Therapies and Takeda to develop PDE1 inhibitors for schizophrenia. Nat Rev Drug Discov 2011; 10: 329

[100] Szatmari SZ, Whitehouse PJ. Vinpocetine for cognitive impairment and dementia. Cochrane Database Syst Rev 2003: CD003119.

[101] Valikovics A, Csanyi A, Nemeth L. Study of the effects of vinpocetin on cognitive functions. Ideggyogy Sz 2012; 65: 115-20.

[102] Hindmarch I, Fuchs HH, Erzigkeit H. Efficacy and tolerance of vinpocetine in ambulant patients suffering from mild to moderate organic psychosyndromes. Int Clin Psychopharmacol 1991; 6: 3143.

[103] Balestreri R, Fontana L, Astengo F. A double-blind placebo controlled evaluation of the safety and efficacy of vinpocetine in the treatment of patients with chronic vascular senile cerebral dysfunction. J Am Geriatr Soc 1987; 35: 425-30.

[104] Subhan Z, Hindmarch I. Psychopharmacological effects of vinpocetine in normal healthy volunteers. Eur J Clin Pharmacol 1985; 28: $567-71$.

[105] Richter Y, Herzog Y, Eyal I, Cohen T. Cognitex supplementation in elderly adults with memory complaints: an uncontrolled open label trial. J Diet Suppl 2011; 8: 158-68.

[106] Thal LJ, Salmon DP, Lasker B, Bower D, Klauber MR. The safety and lack of efficacy of vinpocetine in Alzheimer's disease. J Am Geriatr Soc 1989; 37: 515-20.

[107] Kidd PM. A review of nutrients and botanicals in the integrative management of cognitive dysfunction. Altern Med Rev 1999; 4: 144-61.

[108] Reyes-Irisarri E, Markerink-Van Ittersum M, Mengod G, de Vente J. Expression of the cGMP-specific phosphodiesterases 2 and 9 in normal and Alzheimer's disease human brains. Eur J Neurosci 2007; 25: 3332-8.

[109] Lakics V, Karran EH, Boess FG. Quantitative comparison of phosphodiesterase mRNA distribution in human brain and peripheral tissues. Neuropharmacology 2010; 59: 367-74.

[110] Boess FG, Hendrix M, van der Staay FJ, et al. Inhibition of phosphodiesterase 2 increases neuronal cGMP, synaptic plasticity and memory performance. Neuropharmacology 2004; 47: 1081-92.

[111] Reneerkens OA, Rutten K, Bollen E, et al. Inhibition of phoshodiesterase type 2 or type 10 reverses object memory deficits induced by scopolamine or MK-801. Behav Brain Res 2013; 236: 16-22.

[112] Rodefer JS, Saland SK, Eckrich SJ. Selective phosphodiesterase inhibitors improve performance on the ED/ID cognitive task in rats. Neuropharmacology 2012; 62: 1182-90.

[113] Reneerkens OA, Sambeth A, Blokland A, Prickaerts J. PDE2 and PDE10, but not PDE5, inhibition affect basic auditory information processing in rats. Behav Brain Res 2013; 250: 251-6.

[114] Domek-Lopacinska K, Strosznajder JB. The effect of selective inhibition of cyclic GMP hydrolyzing phosphodiesterases 2 and 5 on learning and memory processes and nitric oxide synthase activity in brain during aging. Brain Res 2008; 1216: 68-77.

[115] Rutten K, Van Donkelaar EL, Ferrington L, et al. Phosphodiesterase inhibitors enhance object memory independent of cerebral blood flow and glucose utilization in rats. Neuropsychopharmacology 2009; 34: 1914-25.

[116] Sierksma AS, Rutten K, Sydlik S, et al. Chronic phosphodiesterase type 2 inhibition improves memory in the APPswe/PS1dE9 mouse model of Alzheimer's disease. Neuropharmacology 2013; 64: 12436.

[117] Sakurai H, Hanyu H, Sato T, et al. Effects of cilostazol on cognition and regional cerebral blood flow in patients with Alzheimer's disease and cerebrovascular disease: a pilot study. Geriatr Gerontol Int 2013; 13: 90-7.

[118] Kai Y, Watanabe M, Morioka M, et al. Cilostazol improves symptomatic intracranial artery stenosis - Evaluation of cerebral blood flow with single photon emission computed tomography. Surg Neurol Int 2011; 2: 8 .

[119] Mochizuki Y, Oishi M, Mizutani T. Effects of cilostazol on cerebral blood flow, P300, and serum lipid levels in the chronic stage of cerebral infarction. J Stroke Cerebrovasc Dis 2001; 10: 63-9.
[120] Birk S, Kruuse C, Petersen KA, et al. The phosphodiesterase 3 inhibitor cilostazol dilates large cerebral arteries in humans without affecting regional cerebral blood flow. J Cereb Blood Flow Metab 2004; 24: 1352-8.

[121] Arai H, Takahashi T. A combination therapy of donepezil and cilostazol for patients with moderate Alzheimer disease: pilot follow-up study. Am J Geriatr Psychiatry 2009; 17: 353-4.

[122] Fatemi SH, King DP, Reutiman TJ, et al. PDE4B polymorphisms and decreased PDE4B expression are associated with schizophrenia. Schizophr Res 2008; 101: 36-49.

[123] Guan F, Zhang C, Wei S, et al. Association of PDE4B polymorphisms and schizophrenia in Northwestern Han Chinese. Hum Genet 2012; 131: 1047-56.

[124] Deng X, Takaki H, Wang L, et al. Positive association of phencyclidine-responsive genes, PDE4A and PLAT, with schizophrenia. Am J Med Genet B Neuropsychiatr Genet 2011; 156B: 850-8.

[125] Millar JK, Wilson-Annan JC, Anderson S, et al. Disruption of two novel genes by a translocation co-segregating with schizophrenia. Hum Mol Genet 2000; 9: 1415-23.

[126] Sachs NA, Sawa A, Holmes SE, et al. A frameshift mutation in Disrupted in Schizophrenia 1 in an American family with schizophrenia and schizoaffective disorder. Mol Psychiatry 2005; 10: 758-64.

[127] Hennah W, Tuulio-Henriksson A, Paunio T, et al. A haplotype within the DISC1 gene is associated with visual memory functions in families with a high density of schizophrenia. Mol Psychiatry 2005; 10: 1097-103.

[128] Millar JK, Pickard BS, Mackie S, et al. DISC1 and PDE4B are interacting genetic factors in schizophrenia that regulate cAMP signaling. Science 2005; 310: 1187-91.

[129] Soda T, Frank C, Ishizuka K, et al. DISC1-ATF4 transcriptional repression complex: dual regulation of the cAMP-PDE4 cascade by DISC1. Mol Psychiatry 2013; 18: 898-908.

[130] Millar JK, Mackie S, Clapcote SJ, et al. Disrupted in schizophrenia 1 and phosphodiesterase 4B: towards an understanding of psychiatric illness. J Physiol 2007; 584: 401-5.

[131] Miyamoto K, Kurita M, Ohmae S, et al. Selective tracheal relaxation and phosphodiesterase-IV inhibition by xanthine derivatives. Eur J Pharmacol 1994; 267: 317-22.

[132] Treves TA, Korczyn AD. Denbufylline in dementia: a double-blind controlled study. Dement Geriatr Cogn Disord 1999; 10: 505-10.

[133] Saletu B, Anderer P, Fischhof PK, et al. EEG mapping and psychopharmacological studies with denbufylline in SDAT and MID. Biol Psychiatry 1992; 32: 668-81.

[134] Folstein MF, Folstein SE, McHugh PR. "Mini-mental state". A practical method for grading the cognitive state of patients for the clinician. J Psychiatr Res 1975; 12: 189-98.

[135] Shader RI, Harmatz JS, Salzman C. A new scale for clinical assessment in geriatric populations: Sandoz Clinical Assessment-Geriatric (SCAG). J Am Geriatr Soc 1974; 22: 107-13.

[136] Wechsler D. Die Messung der Intelligenz Erwachsener. Hans Huber: Bern 1956.

[137] Oswald W, Fleischmann U. Nürnberger Alters-lnventar NAI. Nürnberg: Universität Erlanger-Nürnberg 1982.

[138] Rosen RC, Kostis JB. Overview of phosphodiesterase 5 inhibition in erectile dysfunction. Am J Cardiol 2003; 92: 9M-18M.

[139] Prickaerts J, Sik A, van Staveren WC, et al. Phosphodiesterase type 5 inhibition improves early memory consolidation of object information. Neurochem Int 2004; 45: 915-28.

[140] Reneerkens OA, Rutten K, Akkerman S, et al. Phosphodiesterase type 5 (PDE5) inhibition improves object recognition memory: indications for central and peripheral mechanisms. Neurobiol Learn Mem 2012; 97: 370-9.

[141] Rutten K, Basile JL, Prickaerts J, Blokland A, Vivian JA. Selective PDE inhibitors rolipram and sildenafil improve object retrieval performance in adult cynomolgus macaques. Psychopharmacology (Berl) 2008; 196: 643-8.

[142] Grass H, Klotz T, Fathian-Sabet B, et al. Sildenafil (Viagra): is there an influence on psychological performance? Int Urol Nephrol 2001; 32: 409-12.

[143] Schultheiss D, Muller SV, Nager W, et al. Central effects of sildenafil (Viagra) on auditory selective attention and verbal recognition memory in humans: a study with event-related brain potentials. World J Urol 2001; 19: 46-50.

[144] Reneerkens OA, Sambeth A, Ramaekers JG, et al. The effects of the phosphodiesterase type 5 inhibitor vardenafil on cognitive per- 
formance in healthy adults: a behavioral-electroencephalography study. J Psychopharmacol 2013; 27: 600-8.

[145] Shim YS, Pae CU, Kim SW, et al. Effects of repeated dosing with Udenafil (Zydena) on cognition, somatization and erection in patients with erectile dysfunction: a pilot study. Int J Impot Res 2011; 23(3): 109-14.

[146] Shim YS, Pae CU, Cho KJ, et al. Effects of daily low-dose treatment with phosphodiesterase type 5 inhibitor on cognition, depression, somatization and erectile function in patients with erectile dysfunction: a double-blind, placebo-controlled study. Int J Impot Res 2014; 26(2): 76-80.

[147] Lipina TV, Palomo V, Gil C, Martinez A, Roder JC. Dual inhibitor of PDE7 and GSK-3 - VP1.15 acts as antipsychotic and cognitive enhancer in C57BL/6J mice. Neuropharmacology 2013; 64: 20514.

[148] Perez-Gonzalez R, Pascual C, Antequera D, et al. Phosphodiesterase 7 inhibitor reduced cognitive impairment and pathological hallmarks in a mouse model of Alzheimer's disease. Neurobiol Aging 2013; 34: 2133-45.

[149] van der Staay FJ, Rutten K, Barfacker L, et al. The novel selective PDE9 inhibitor BAY 73-6691 improves learning and memory in rodents. Neuropharmacology 2008; 55: 908-18.

[150] Kleiman RJ, Chapin DS, Christoffersen C, et al. Phosphodiesterase 9A regulates central cGMP and modulates responses to cholinergic and monoaminergic perturbation in vivo. J Pharmacol Exp Ther 2012; 341: 396-409.

[151] Hutson PH, Finger EN, Magliaro BC, et al. The selective phosphodiesterase 9 (PDE9) inhibitor PF-04447943 (6-[(3S, 4S)-4methyl-1-(pyrimidin-2-ylmethyl)pyrrolidin-3-yl]-1-(tetrahydro-2Hpy ran-4-yl)-1, 5-dihydro-4H-pyrazolo[3, 4-d]pyrimidin-4-one) enhances synaptic plasticity and cognitive function in rodents. Neuropharmacology 2011; 61: 665-76.

[152] Vardigan JD, Converso A, Hutson PH, Uslaner JM. The selective phosphodiesterase 9 (PDE9) inhibitor PF-04447943 attenuates a scopolamine-induced deficit in a novel rodent attention task. J Neurogenet 2011; 25: 120-6.

[153] Bramon E, Rabe-Hesketh S, Sham P, Murray RM, Frangou S. Meta-analysis of the P300 and P50 waveforms in schizophrenia. Schizophr Res 2004; 70: 315-29.

[154] Schwam E, Evans R, Nicholas T, et al. PF-04447943: a phase II controlled clinical trial of a selective PDE9A inhibitor in Alzheimer's disease. Alzheimer's Dementia 2011; 7: S695.

[155] Fujishige K, Kotera J, Michibata H, et al. Cloning and characterization of a novel human phosphodiesterase that hydrolyzes both cAMP and cGMP (PDE10A). J Biol Chem 1999; 274: 18438-45.

[156] Loughney K, Snyder PB, Uher L, et al. Isolation and characterization of PDE10A, a novel human 3', 5'-cyclic nucleotide phosphodiesterase. Gene 1999; 234: 109-17.

[157] Soderling SH, Bayuga SJ, Beavo JA. Isolation and characterization of a dual-substrate phosphodiesterase gene family: PDE10A. Proc Natl Acad Sci USA 1999; 96: 7071-6.
[158] Grauer SM, Pulito VL, Navarra RL, et al. Phosphodiesterase 10A inhibitor activity in preclinical models of the positive, cognitive, and negative symptoms of schizophrenia. J Pharmacol Exp Ther 2009; 331: 574-90.

[159] Rodefer JS, Murphy ER, Baxter MG. PDE10A inhibition reverses subchronic PCP-induced deficits in attentional set-shifting in rats. Eur J Neurosci 2005; 21: 1070-6.

[160] Gage JL, Onrust R, Johnston D, et al. N-Acylhydrazones as inhibitors of PDE10A. Bioorg Med Chem Lett 2011; 21: 4155-9.

[161] Gleason SD, Shannon HE. Blockade of phencyclidine-induced hyperlocomotion by olanzapine, clozapine and serotonin receptor subtype selective antagonists in mice. Psychopharmacology (Berl) 1997; 129: 79-84.

[162] Schmidt CJ, Chapin DS, Cianfrogna J, et al. Preclinical characterization of selective phosphodiesterase $10 \mathrm{~A}$ inhibitors: a new therapeutic approach to the treatment of schizophrenia. J Pharmacol Exp Ther 2008; 325: 681-90.

[163] Siuciak JA, Chapin DS, Harms JF, et al. Inhibition of the striatumenriched phosphodiesterase PDE10A: a novel approach to the treatment of psychosis. Neuropharmacology 2006; 51: 386-96.

[164] Hebb AL, Robertson HA, Denovan-Wright EM. Phosphodiesterase $10 \mathrm{~A}$ inhibition is associated with locomotor and cognitive deficits and increased anxiety in mice. Eur Neuropsychopharmacol 2008; 18: 339-63.

[165] Smith SM, Uslaner JM, Cox CD, et al. The novel phosphodiesterase 10A inhibitor THPP-1 has antipsychotic-like effects in rat and improves cognition in rat and rhesus monkey. Neuropharmacology 2013; 64: 215-23.

[166] DeMartinis NA. Results of a phase 2a proof-of-concept trial with a PDE10A inhibitor in the treatment of acute exacerbation of schizophrenia. Biol Psychiatry 2012; 71: 17S.

[167] Buchanan RW, Keefe RS, Umbricht D, et al. The FDA-NIMHMATRICS guidelines for clinical trial design of cognitiveenhancing drugs: what do we know 5 years later? Schizophr Bull 2011; 37: 1209-17.

[168] Kuroiwa M, Snyder GL, Shuto T, et al. Phosphodiesterase 4 inhibition enhances the dopamine D1 receptor/PKA/DARPP-32 signaling cascade in frontal cortex. Psychopharmacology (Berl) 2012; 219: 1065-79.

[169] Jones CA, Watson DJ, Fone KC. Animal models of schizophrenia Br J Pharmacol 2011; 164: 1162-94.

[170] Aleman A, Hijman R, de Haan EH, Kahn RS. Memory impairment in schizophrenia: a meta-analysis. Am J Psychiatry 1999; 156: 1358-66.

[171] Brebion G, Gorman JM, Malaspina D, Sharif Z, Amador X. Clinical and cognitive factors associated with verbal memory task performance in patients with schizophrenia. Am J Psychiatry 2001; 158: 758-64.

[172] Zhang HT. Phosphodiesterase Targets for Cognitive Dysfunction and Schizophrenia--a New York Academy of Sciences Meeting. IDrugs 2010; 13: 166-8. 